

\title{
O pluralismo jurídico e efetividade jurídica na relação entre proteção ambiental e investimentos estrangeiros: os casos Santa Elena, Metalclad e Tecmed ${ }^{*}$
}

\author{
Legal pluralism and legal effectiveness in \\ the relationship between environmental \\ protection and foreign investment: Santa \\ Elena, Metalclad and Tecmed cases
}

\section{Resumo}

Trata-se de uma análise da efetividade jurídica considerando alguns dos efeitos da globalização no direito, especificamente, efeitos de um pluralismo jurídico que integra diferentes ordens, estatais e não estatais ou mistas. Diante desse contexto pluralista, percebe-se que a integração entre essas ordens torna-se elemento chave para a efetividade jurídica de uma e de outra. Com essas considerações, busca-se pesquisar a efetividade jurídica na relação entre dois regimes jurídicos quase incomensuráveis, que são a proteção jurídica estatal e a proteção aos investimentos estrangeiros. Tal análise é feita por meio do estudo de três casos no Centro Internacional para a Resolução de Conflitos sobre Investimentos (do inglês - ICSID), os casos Santa Elena, Metalclad e Tecmed. Desses casos, algumas questões de teoria do direito e de efetividade jurídica são estudadas, demonstrando-se a insuficiência da teoria estatal do direito e a pertinência de se partir de um conceito pluralista do direito mesmo no âmbito da proteção ambiental, que é direito estatal por excelência. Além disso, tais casos nos permitem questionar como melhorar a efetividade jurídica ambiental em um campo em que o Estado tem sua ação relativizada por atores transnacionais em favor da proteção de investimentos estrangeiros. Para tanto, é preciso compreender a interação existente entre os diferentes regimes, suas regras e a necessidade de se integrar normas mais adequadas à relação entre os investimentos estrangeiros e a proteção ambiental.

Palavras-chave: Pluralismo jurídico. Efetividade jurídica. Proteção ambiental. Investimentos estrangeiros. ICSID.

\footnotetext{
* Artigo recebido em 11/12/2012

Artigo aprovado em 25/01/2013

1 Doutoranda em Direito (UNICEUB - Brasília/ DF em cotutela com a Université Aix-Marseille III/França), Mestre em Direito (UNICEUBBrasília/DF), Especialista em Direito Internacional Ambiental (UNITAR-UNEP). Email: gblima@gmail.com
} 
three cases at the International Centre for Settlement of Investment Disputes ICSID): Santa Elena, Metalclad and Tecmed. Some questions of legal theory and legal effectiveness are studied, demonstrating the inadequacy of state law theory and relevance of the legal pluralism to legal studies even in the context of environmental protection, which is state-law field. Furthermore, these cases allow us to question how to improve the legal effectiveness of the environment protection, in a field where the state is relativized by transnational actors in favor of protection of foreign investments. For that, it is important to understand the interaction between the different regimes, rules and the need to integrate better rules to the relationship between foreign investment and environmental protection.

Keywords: Legal Pluralism. Legal effectiveness. Environmental protection. Foreign investment. ICSID.

\section{Introdução}

Possibilidades e limites para o Estado diante de um pluralismo jurídico: a proteção ambiental estatal diante da proteção jurídica de investimentos estrangeiros

Já não é rara a influência nas legislações nacionais e na ação estatal das movimentações no direito internacional. Os Estados cada vez mais procuram se adequar aos ditames de decisões internacionais em diversas esferas jurídicas e sociais. Nas Comunidades Europeias, os juízes nacionais já não podem aplicar uma regra que vá contra o direito comunitário. No comércio internacional, a uniformização das legislações segue os ditames da Organização Mundial do Comércio, e cada vez mais o direito nacional sofre influência de regimes jurídicos autônomos diversos. ${ }^{2}$

A adaptação das legislações nacionais ocorre ainda diante de ações privadas, estas sendo mais difíceis de analisar, se seguirmos as insuficientes explicações oferecidas pelas teorias jurídicas tradicionais, que, em larga medida, partem da explicação estatal do direito; em que

\footnotetext{
2 Segue-se o conceito de Krasner, em que os regimes internacionais se estruturam nos princípios, normas, regras e decisões, reflexos da convergência de interesses dos seus atores. São específicos no que se refere à matéria e ao modo de tratá-la, adquirindo uma verdadeira autonomia, uma sistêmica própria, descentralizando também o processo de efetivar a norma. KRASNER, Stephen D. Structural conflict: The third world against global liberalism. University of California Press, p. 04.
}

o objeto da pesquisa jurídica é a norma fruto do Estado ou da relação entre Estados. Já não é mais tão recente assim o aparecimento de diferentes ordens diferentes da ordem estatal, a serem chamadas de transnacionais, com a formação de normas jurídicas por outras vias diferentes da via estatal, a exemplo da lex mercatória ${ }^{3}$ e a arbitragem internacional. ${ }^{4}$

Os efeitos de pluralidade no direito: pluralidade de atores a constituírem normas jurídicas, pluralidade de questões que interagem entre si, pela relação dessas diferentes normas jurídicas, são efeitos da globalização ${ }^{5}$ no campo jurídico. Questões como a mundialização, ${ }^{6}$ a

3 Lex mercatória é aqui considerada o direito transnacional das transações econômicas, exemplo de um direito global fora da ordem estatal. TEUBNER, Gunter. Global Bukowina: Legal Pluralism in the World Society. In: GUNTHER Teubner (Ed.). Global Law Without a State. Dartmouth, Aldershot 1997. p. 3-28.

4 Fischer-Lescano e Gunther Teubner demonstra a pluralidade de ordens jurídicas não apenas pela lex mercatória, mas já também face a movimentos da lex digitalis, para o tratamento da internet e a lex constructionis no ramo da engenharia. FISCHER-LESCANO, Andreas; TEUBNER, Gunter. Regimes-Collisions: the vain search for legal unity in the fragmentation in global law. Translatet by Michelle Everson. Michigan Journal of International Law, v. 25, n. 999, p. 199-1046, ,

5 Como conceito de globalização, adota-se uma perspectiva geral que caracteriza o fenômeno da velocidade e caráter expansivo da formação das diversas relações econômicas, jurídicas ou/e políticas. BECK, Ulrich. O que é globalização? Equívocos do globalismo: respostas à globalização. Tradução de André Carone. São Paulo: Paz e Terra, 1999. p. 08-09.

6 Os termos globalização e mundialização, para este artigo, não são considerados sinônimos. Globalização é o fenômeno geral de formação e expansão de diversas relações econômicas, jurídicas, políticas etc. Mundialização, por sua vez, pode ser entendida como a universalização de valores, o que é apenas um dos efeitos da globalização, tal como o explica Delmas Marty. Por outro lado, tal distinção - ainda que útil em fins didáticos - é fácil de ser criticada, uma vez que pode ser considerado difícil um fenômeno de globalização sem efeitos de universalização de valores. Mas, justamente por fins didáticos, a distinção aqui é adotada para distinguir diferentes objetos dentre os efeitos que podem surgir de uma globalização: é possível analisar os efeitos de um fenômeno de globalização pelo estudo dos valores e, daí, da universalização, com forte ênfase moral, é possível também estudar os aspectos jurídicos e normativos da globalização, pelos seus efeitos na formação, eficácia e efetividade da norma jurídica. Nesse sentido, reconhece-se, portanto, que embora possam ser vistos como conceitos distintos, não são fenômenos necessariamente independentes um do outro. DELMAS-MARTY, Mireille. Trois défis pour un droit mondial. Tradução Livre. Paris: Éditions du Seuil, novembre 1998. 
internacionalização dos direitos ${ }^{7}$ e o pluralismo jurídico são fenômenos mais que evidentes.

Diferentes aspectos desse efeito de pluralidade e uma influência entre os direitos encontram-se presente como desafio para o estudo do direito. No campo de repercussão de atores públicos e privados, por exemplo, o papel do indivíduo no direito internacional, sugerindo uma crise de identidade para a teoria estatal, faz parte do estudo de André Gontijo neste livro; Karla Margarida demonstra a tensão entre os movimentos de cartéis que se fazem de forma transnacional e o Estado como ator importante para servir de freio diante de tais movimentos globais; Marlon Tomazette apresenta um estudo sobre o ressurgimento da lex mercatoria, aspecto talvez mais notório do pluralismo jurídico cujo conceito aqui é ligado aos efeitos da globalização no direito; ${ }^{8}$ além disso, no campo de reconstrução do Estado, Christiani Buani procura ressaltar a importância da relação da justiça de transição e os processos de internacionalização dos direitos, demonstrando a influência que uma ordem jurídica pode exercer em outra. Aspectos relacionados com essa tensão

\footnotetext{
7 A internacionalização dos direitos em si não é objeto do presente estudo, mas, em resumo, comporta técnicas de unificação, uniformização e harmonização para compreender diferentes relações entre o direito internacional e o direito interno. A compreensão do assunto é facilitada pelo estudo de Delmas-Marty, ponto de partida nos estudos de internacionalização do direito, que explica esses processos de internacionalização, nos quais, a unificação é raramente espontânea, normalmente estabelecida pelo direito internacional, pelos tratados, e exige a sua inserção no direito nacional; a uniformização é um processo diferente que consiste em adaptar os direitos nacionais às regras definidas pelas convenções internacionais, sendo que cada ordenamento mantém sua identidade, suas técnicas, que então veiculam a aplicação de uma regra internacional comum. A harmonização, entretanto, é ordenada diante da impossibilidade de identidade ou de proximidade entre os sistemas, diante de diferenças que são julgadas incompatíveis. DELMAS-MARTY, Mireille. Trois défis pour un droit mondial. Tradução Livre. Paris: Éditions du Seuil, novembre 1998. p. 118.

8 O pluralismo jurídico destaca-se por analisar o conflito de forma sistêmica, ou seja, na compreensão das lógicas normativas envolvidas, que podem se diferir e entrarem em conflito. No que diz respeito às características, no pluralismo jurídico, o direito será direito porque as partes assim o consideraram e porque o âmbito jurídico assim o trata. TEUBNER, Gunter. Global Bukowina: Legal Pluralism in the World Society. In: GUNTHER Teubner (Ed.). Global Law Without a State. Dartmouth, Aldershot 1997. Para entender as diferentes clivagens existentes sobre o pluralismo jurídico: WOLKMER, Antônio Carlos; VERAS NETO, Francisco Q.; LIXA, Ivone M. Pluralismo jurídico. Os novos caminhos da contemporaneidade. São Paulo: Saraiva, 2011.
}

entre Estado e atores não estatais e a influência entre ordens jurídicas são, nesse sentido, parte entre os aspectos atuais do campo da internacionalização dos direitos.

Seguindo a proposta do presente livro, este estudo busca explorar os reflexos da globalização no direito, oriundos dessa tensão entre Estado e atores não estatais, assim como a influência que um regime jurídico pode exercer em outro. Tais aspectos são aqui analisados na relação entre investimentos estrangeiros e a proteção ambiental estatal. Parar ilustrar este campo de pesquisa, a pesquisa foca em alguns estudos de caso no campo do Centro Internacional para a Resolução de Conflitos sobre Investimentos (do inglês - ICSID), a partir de três breves estudos de casos: Santa Elena, Metalclad e Tecmed.

A Compañía del Desarrollo de Santa Elena, S.A. (“CDSE”), empresa da Costa Rica, cuja maioria dos shareholdes era americana, levou o governo da Costa Rica para a arbitragem no ICSID, em 1995. A arbitragem foi levantada para decidir o valor da compensação da expropriação da propriedade conhecida como "Santa Elena", da Companhia desde 1970, expropriação para fins de proteção ambiental. O tribunal arbitral seguiu com a análise do valor da compensação, dentre outros argumentos, alegando que o objetivo de proteção ambiental, embora motivo de interesse geral e, portanto, legítimo para a expropriação, não alterava a obrigação de indenização devida. ${ }^{9}$

Em outubro de 1996, a Metalclad Corporation, empresa dos Estados Unidos, investia em um centro de tratamento de resíduos tóxicos no México, demandou contra ele no tribunal arbitral do ICSID, afirmando que a recusa mexicana de renovação da licença de exploração era uma afronta aos seus investimentos, por não ter concedido tratamento justo e equitativo, e diante de medida equivalente à expropriação, de acordo com o artigo 1110 do Acordo Norte-Americano de Livre Comércio (NAFTA). O México havia fundado tal recusa ante aos riscos ecológicos da atividade, e, em 30 de agosto de 2000, o tribunal ordenou que o pagamento de indenização de mais de US\$16 milhões à Metalclad, e que esta última transferisse a propriedade do imóvel ao governo mexicano. ${ }^{10}$

9 ICSID. Santa Elena S.A. X Costa Rica, Caso No. ARB/96/1. Disponível em: <http://icsid.worldbank.org/ICSID/FrontServlet> . Acesso em: 10 fev. 2012.

${ }^{10}$ ICSID. Metalclad x México. Caso No. ARB(AF)/97/1). Disponível em:<http://icsid.worldbank.org/ICSID/FrontServlet $>$. Acesso em 10 fev. 2012. 
Em caso semelhante, o México foi demandado no ICSID pela empresa espanhola Tecmed, por ter decidido não mais renovar a autorização que permitia o funcionamento envolvendo investimentos de sua subsidiária Cytrar, na aquisição e operação de um confinamento de resíduos tóxicos. Em maio de 2003, o tribunal emitiu laudo em que afirmou que o México feriu com o tratamento justo e equitativo com a empresa estrangeira, tendo sua ação efeitos de expropriação. Por fim, o laudo outorgou à empresa o pagamento de US\$ 5,533 milhões por indenização, devendo ela transmitir a propriedade ao governo mexicano. ${ }^{11}$

O que esses casos têm em comum é que atitudes de governos, em seu poder de regulamentação em nome de riscos ambientais, foram responsáveis por violações a investimentos estrangeiros, sendo questionadas no ICSID. A arbitragem no ICSID institucionaliza a possibilidade de uma relação entre Estado e entidade privada, tal como os casos apresentados anteriormente. Esses casos são capazes de ilustrar a necessidade de alteração da legislação nacional em matéria ambiental, por repercutir em uma ordem jurídica diversa.

Tais casos demonstram que a proteção ambiental é relativizada pela proteção dos investimentos estrangeiros; que uma ordem estatal é relativizada na sua interação com uma ordem transnacional; ${ }^{12}$ que a atuação do Estado é relativizada pela atuação de entidades privadas. Nesse contexto, é possível questionar quais são os limites e possibilidades para a atuação estatal em face dos efeitos da globalização? Precisamente, quais os limites e possibilidades para a proteção jurídica ambiental em face da proteção dos investimentos estrangeiros?

Com essas perguntas, tais casos trazem, então, elementos interessantes para a teoria do direito e para o estudo da efetividade jurídica. Do ponto de vista da teoria do direito, ilustram uma necessária superação do paradigma do direito estatal para um pluralismo jurídico. No que se refere à efetividade do direito, ilustram os limites e possibilidades da proteção ambiental na sua relação com

\footnotetext{
${ }^{11}$ ICSID. Tecmed x México. Disponível em: < http://ictsd.org/i/ news/4427/ >. Acesso em: 01 nov. 2011.

${ }^{12}$ De modo geral, as ordens transnacionais aqui caracterizam uma ordem em que o Estado não é o centro e nem o provedor da ordem. Trata-se de uma posição conceitual para diferenciar a ordem transnacional também do direito internacional privado.
}

a proteção dos investimentos estrangeiros. Assim, primeiro busca-se fazer a análise dos casos, para, em seguida, analisarem-se os pontos relacionados ao pluralismo jurídico, de um lado, e a efetividade jurídica da proteção ambiental, de outro lado.

\section{Os casos Metalclad, Tecmed e Santa Elena: pluralismo jurídico e efetividade da proteção do meio ambiente}

Os casos Metalclad, Tecmed e Santa Elena ilustram atitudes de governos, em seu poder de regulamentação em nome de riscos ambientais, que foram responsáveis por violações a investimentos estrangeiros, sendo questionadas no ICSID. Os casos são exemplo de conflito entre uma ordem estatal e a participação privada. O Estado tem sua capacidade de atuação relativizada perante a proteção do interesse dos investidores. Além disso, a proteção ambiental é também relativizada pela proteção dos investimentos estrangeiros.

\subsection{O caso Santa Elena x Costa Rica}

Em 2 de junho de 1995, o ICSID recebeu um requerimento para arbitragem da CDSE, empresa da Costa Rica com a maioria dos investidores oriunda dos Estados Unidos. A disputa dizia respeito à compensação devida à empresa, em razão de expropriação da propriedade de nome "Santa Elena", por parte do governo da Costa Rica.

O governo da Costa Rica havia emitido Decreto expropriando a propriedade Santa Elena, em 1978, decidindo que ela passaria a ser parte do Parque Nacional da Costa Rica, embora de fato fosse ficar com a CDSE. A propriedade era composta por mais de 30 quilômetros da costa do Pacífico, na Costa Rica, abundante em fauna e flora silvestre, foi adquirida pela CDSE no valor de EU\$ 395.000 em 1970 e passou a aplicar um programa de desenvolvimento da terra para fins turísticos e residenciais.

O motivo da expropriação era alcançar o objetivo de conservação de recursos ambientais, acrescentando a propriedade Santa Elena ao Parque Nacional de Santa Rosa. A medida foi tomada porque as terras do Parque eram insuficientes para manter estáveis populações de animais da fauna típica da região, como pumas e jaguares. A expropriação foi declarada, com o valor da Compensação em seis milhões, quatrocentos e cinquenta mil Colônias $(6.450 .000,00)$, aproximadamente U.S. \$1,900,000. 
Destaca-se o Decreto in verbis:

"Whereas:

1. The current area of the Santa Rosa National Park is insufficient to maintain stable populations of large feline species such as pumas and jaguars, and that a substantial area needs to be added to it if it is to carry out its conservationist objectives.

2. The lands situated to the north of the Santa Rosa National Park contain flora and fauna of great scientific, recreational, educational, and tourism value, as well as beaches that are especially important as spawning grounds for sea turtles.

3. To meet these objectives, the Government of the Republic requires the property that belongs to the Compañia de Desarrollo Santa Elena S.A. registered in the Public Register, Property Section, District of Guanacaste, tome 1975, folio 321, entries 2-3, number 24,165, located in the fourth district of Santa Elena, canton 10, La Cruz, province of Guanacaste, which is currently used for stock breeding and other uses, and has several facilities; with a total area of 15,800 hectares, with the following bounds: to the north, the Hacienda Murciélago; to the south, Pacific Ocean and Santa Rosa National Park; to the east, the Pan American Highway and the Santa Rosa National Park; and to the west, the Pacific Ocean.

\section{$[\ldots]$}

\section{DECREE:}

Article 1: Based on law thirty-six, of June 26, 1896,supplemented by Legislative Decree seventy-eight of June 24,1934 , the property owned by the Compañia de Desarrollo Santa Elena S.A. described in the third whereas clause of this decree, is hereby expropriated.

Article 2: The price to be paid for said real property shall be sixteen million, four hundred fifty thousand colones, all in cash, pursuant to special appraisal No. 15581-A.V.E. of April 14, 1978, by the General Bureau of Direct Taxation; this amount shall be provided by the Family Allocations Program for this purpose.

Article 3: The Attorney General of the Republic is authorized to formalize the respective deed and register the real property in the name of the state, under the administration of the National Parks Service of the Ministry of Agriculture.

Article: It shall take effect as of May 5, 1978.

Done at the Casa Presidenciál. San José.

May 5, 1978." ${ }^{13}$

\footnotetext{
${ }^{13}$ ICSID. Santa Elena S.A. X Costa Rica, Caso No. ARB/96/1. Disponível em: <http://icsid.worldbank.org/ICSID/FrontServlet $>$. Acesso em: 10 fev. 2012.
}

A expropriação não foi questionada pela CDSE, reconhecendo-se seu motivo como de ordem pública que, mediante indenização justa, era justificável. Todavia, a CDSE não concordava com o valor da compensação oferecido pela Costa Rica, tendo feito sua própria avaliação em EU\$ 6.4000,000. ${ }^{14}$

No período aproximado de 20 anos a contar de 1978 , as partes tentaram resolver a questão do valor da compensação nas Cortes Nacionais da Costa Rica, sem sucesso. A CDSE passou a insistir em levar a questão para o ICSID, que o governo da Costa Rica cedeu mediante pressão da CDSE, inclusive pressão política e ameaça de cortes de financiamentos, pelo uso de um Decreto Norte Americano, de 1994, conhecido como o "Helms Amendment". Tal Decreto proibia a aprovação de financiamento, por instituições financeiras internacionais, para um país que expropriou propriedade de um cidadão dos Estados Unidos ou Corporação com pelo menos 50\% das ações de propriedade de cidadãos norte-americanos, medida a ser aplicada ao país que não tenha tomado medidas, ou de retorno da propriedade, ou de pagamento de compensação ou de proceder com uma arbitragem no ICSID para resolver a questão.

Um tribunal do ICSID foi então acionado, e, na demanda, a CDSE pediu o valor de E.U.\$ 40.000,000 para a compensação. Apreciou três principais questões: o direito aplicável, a determinação do valor justo para a compensação e a época a ser considerada para a determinação desse valor justo. Porque não havia contratos entre as partes, o tribunal determinou aplicar suas regras (Convenção do ICSID) e as do direito internacional, ao invés das regras da Costa Rica. ${ }^{15}$

O tribunal não entrou no motivo da expropriação, também considerou irrelevante o tamanho da propriedade para a discussão da compensação. O que deveria ser respondido era qual o montante justo para a compensação: se era o valor oferecido pelo governo da Costa Rica, ou o valor dado pela empresa.

${ }^{14}$ ICSID. Santa Elena S.A. X Costa Rica, Caso No. ARB/96/1. Disponível em: <http://icsid.worldbank.org/ICSID/FrontServlet>. Acesso em: 10 fev. 2012.

${ }^{15}$ ICSID. Santa Elena S.A. X Costa Rica, Caso No. ARB/96/1. Disponível em: <http://icsid.worldbank.org/ICSID/FrontServlet $>$. Acesso em: 10 fev. 2012. 
Ressalta-se que, ainda que o motivo da expropriação não fosse central, a questão ambiental foi parte da análise de qual seria o valor justo da compensação. Entrou na discussão se o motivo "proteção ambiental" interferia no conceito do que seria o valor justo. O governo da Costa Rica defendia que o valor justo para essa compensação era o valor com base no preço de mercado, considerando que a legislação ambiental existente restringiria significantemente o desenvolvimento comercial de Santa Elena. A empresa se defendeu argumentando que o preço de mercado deveria ser estabelecido sem levar em conta qualquer legislação. ${ }^{16}$

Nesse sentido, o tribunal considerava importante a definição do que era justo, adequado, apropriado, razoável. Sobre isso, sua interpretação seguia no sentido de que a compensação a ser paga deveria ser baseada no valor justo de mercado da propriedade, calculada com referência ao seu mais alto e melhor uso. Assim, segue a decisão do ICSID:

\section{$[\ldots]$}

The vocabulary describing the amount of compensation properly payable in respect of a lawful taking has varied considerably from time to time. It comprises such words as "full", "adequate", "appropriate", "fair" and "reasonable". Sometimes, the descriptive adjective is elaborated by the additional mention of "market value".

In the present case, the Tribunal is spared the need to enter further into any doctrinal discussion of the standard of compensation because it is common ground between the parties, and the Tribunal agrees, that the compensation to be paid should be based upon the fair market value of the Property calculated by reference to its "highest and best use" [...]. ${ }^{17}$

O tribunal explicou que, ainda que o governo da Costa Rica de fato tinha o direito de expropriar por motivo de ordem pública, o motivo de conservação ambiental não afetava nem a natureza da expropriação, nem a compensação que deveria ser paga. O propósito de proteção ambiental não afetava o caráter legal da obrigação de uma compensação adequada. Na letra da decisão:

${ }^{16}$ ICSID. Santa Elena S.A. X Costa Rica, Caso No. ARB/96/1. Disponível em: <http://icsid.worldbank.org/ICSID/FrontServlet>. Acesso em: 10 fev. 2012.

${ }^{17}$ ICSID. Santa Elena S.A. X Costa Rica, Caso No. ARB/96/1. Disponível em: <http://icsid.worldbank.org/ICSID/FrontServlet $>$. Acesso em: 10 fev. 2012 $[\ldots]$

While an expropriation or taking for environmental reasons may be classified as a taking for a public purpose, and thus may be legitimate, the fact that the Property was taken for this reason does not affect either the nature or the measure of the compensation to be paid for the taking $[\ldots] \cdot{ }^{18}$

Nesse sentido, o que era importante para o estabelecimento do valor da compensação não era o motivo da expropriação, mas a sua existência em si. A expropriação, por medidas ambientais, equiparava-se com qualquer outra medida expropriatória. Nesse sentido, a obrigação do Estado em pagar uma compensação permanece, não fazendo diferença se as partes possuem também obrigação de proteger o meio ambiente. Nos termos do tribunal:

\section{$[\ldots]$}

the purpose of protecting the environment for which the Property was taken does not alter the legal character of the taking for which adequate compensation must be paid. The international source of the obligation to protect the environment makes no difference.

72. Expropriatory environmental measuresno matter how laudable and beneficial to society as a whole-are, in this respect, similar to any other expropriatory measures that a state may take in order to implement its policies: where property is expropriated, even for environmental purposes, whether domestic or international, the state's obligation to pay compensation remains $[\ldots] .^{19}$

Também foi elemento chave para a definição do valor justo qual era a época a ser considerada para analisar o valor da propriedade em seu uso mais eficaz. A empresa considerava que o valor justo de mercado seria baseado no valor à época da disputa, enquanto o governo da Costa Rica defendia que o valor da compensação deveria ser com base no preço de mercado na data do Decreto de expropriação, em 1978.

O tribunal explicou que não havia critério automático sobre qual data deveria ser utilizada. A expropriação seria avaliada a partir da data em que a interferência governamental privou o proprietário dos seus direitos.

\footnotetext{
${ }^{18}$ ICSID. Santa Elena S.A. X Costa Rica, Caso No. ARB/96/1. Disponível em: <http://icsid.worldbank.org/ICSID/FrontServlet>. Acesso em: 10 fev. 2012.

${ }^{19}$ ICSID. Santa Elena S.A. X Costa Rica, Caso No. ARB/96/1. Disponível em: <http://icsid.worldbank.org/ICSID/FrontServlet> . Acesso em: 10 fev. 2012.
} 
Seguindo nesse sentido, o tribunal entendeu que a expropriação pelo Decreto de 5 de maio de 1978 determina a tomada da propriedade, o início da interferência do governo mexicano nos direitos da empresa. A partir do Decreto, a propriedade já não poderia mais ser utilizada para os seus propósitos, pelos quais foi originalmente adquirida. ${ }^{20}$

Definido o momento a ser considerado para o cálculo do valor da compensação como sendo a partir do Decreto de expropriação, o tribunal passa para a definição do seu valor. Para tal análise, entrava em consideração a avaliação da propriedade ou dos direitos de propriedade em relação ao seu interesse econômico, ou seja, diante do lucro que deixou de ter, mas levando as circunstâncias do caso em consideração. Tais circunstâncias, em suma, dizem respeito ainda que a empresa tenha tido seus direitos limitados, pois ela continuou no uso da propriedade. Segundo o tribunal, a determinação do interesse, levando em questão as circunstâncias do caso, tornava desnecessária uma separação clara entre o valor da compensação e o valor dos lucros que deixou de ganhar, englobando ambos. Por fim, definiu que o valor a ser pago pela compensação seria o de U.S. $\$ 16,000,000 .^{21}$

Dos elementos jurídicos importantes a serem ressaltados, destaca-se que o caso é capaz de ilustrar a atuação estatal de proteção ambiental, caracterizando violação à investimento estrangeiro, frente ao ICSID. A caracterização da violação reflete na relativização do poder de regulamentação do Estado. Diferentes aspectos integram essa relativização, mas o que o caso destaca é a insuficiência da atuação estatal que foi incapaz de resolver a demanda internamente, além da própria complexidade da relação da lógica da proteção ambiental entre a lógica econômica da proteção dos investimentos estrangeiros.

No caso em questão, a demanda foi levada a um tribunal do ICSID diante da insuficiência da atuação estatal para lidar com questões globalizadas, como a proteção

${ }^{20}$ ICSID. Santa Elena S.A. X Costa Rica, Caso No. ARB/96/1. Disponível em: http://icsid.worldbank.org/ICSID/FrontServlet. Acesso em: 10 fev. 2012.

${ }^{21}$ Para a definição do valor da compensação, entra em questão o elemento da definição do interesse para definir a compensação e a extensão do dano econômico. Tal discussão, embora interessante, não entra na análise em questão, razão pela qual o presente artigo a apresenta de forma resumida. ICSID. Santa Elena S.A. X Costa Rica, Caso No. ARB/96/1. Disponível em: <http://icsid.worldbank.org/ICSID/FrontServlet>. Acesso em: 10 fev. 2012. dos investimentos. A insuficiência jurídica estatal é facilmente ilustrada diante da morosidade dos instrumentos nacionais, em especial, o judiciário.

Além disso, o caso mostra que o fato de ter sido a expropriação para efetivar determinada proteção ambiental não tira a responsabilidade de compensar, objeto da demanda em questão. A lógica ambiental não prevalece perante a obrigação de indenizar, instituto jurídico de lógica econômica. Faltam mais consideração com elementos ambientais no regime de proteção dos investimentos, mais flexibilidade e regras mais adequadas a tal situação de repercussão entre as normas.

Esses aspectos que o caso Santa Elena apresenta, aspectos na relação entre meio ambiente e proteção dos investimentos estrangeiros, são ressaltados de modo semelhante nos outros casos demonstrados a seguir.

\subsection{0 caso Metalclad x México}

Metalclad, empresa dos Estados Unidos, integrava a Eco-Metalclad Corporation, também empresa dos Estados Unidos, que detinha $100 \%$ das ações da Ecossistemas Nacionais SA (ECONSA), uma corporação mexicana. Em 1993, a ECONSA comprou a companhia mexicana ConfinamientoTecnico de Resíduos Industriales SA (CONTERIN), para aquisição, desenvolvimento e operação de resíduos perigosos dessa estação de transferência e aterro no vale de La Pedrera, em Galdacazar.

CONTERIN era a proprietária do registro da propriedade do confinamento, bem como das autorizações e licenças que eram a base dessa disputa no ICSID..$^{22} \mathrm{CO}$ TERIN era a empresa, em benefício da qual, METALCLAD, apresentando-se como "investidora de uma das partes", apresentou um pedido de arbitragem sob o NAFTA, artigo 1117.

O Confinamento situava-se em uma área de 814 hectares, localizada a $70 \mathrm{Km}$ da cidade de Gualdacázar. Aproximadamente 800 pessoas viviam em uma área de dez quilômetros de aterro, que teve a construção finalizada em 1995. ${ }^{23}$ O problema foi quando o Município onde se localizava o empreendimento exigiu outra licença para funcionamento.

${ }^{22}$ ICSID. Tecmed x México. Disponível em: <http://ictsd.org/i/ news/4427/>. Acesso em: 10 fev. 2012.

${ }^{23}$ ICSID. Tecmed x México. Disponível em: <http://ictsd.org/i/ news/4427/>. Acesso em: 10 fev. 2012. 
Metalclad alegou que o governo do México, por intermédio do governo estadual de San Luiz Potosi e do governo local de Guadalcazar, interferiu no seu desenvolvimento e operação do aterro de resíduos perigosos. Alegou que a interferência violava o capítulo XI das provisões de investimento do Tratado de Livre Comércio da América do Norte, no NAFTA, especificamente, violação ao tratamento justo e equitativo entre os investidores (artigo 1105), ${ }^{24}$ assim como o artigo $1110,{ }^{25}$ ao tomar medida equivalente à expropriação dos investimentos feitos pela empresa.

O artigo 1110 legitima medidas com efeito de expropriação, desde que tenham sido tomadas em caso de utilidade pública, sobre bases não discriminatórias, e mediante indenização. A violação se deu no momento em que o México, pelo governo local, negou a renovação da licença para a operação do aterro, ainda que já existissem licenças estaduais e federais envolvidas, alegando motivos de proteção ambiental, não tendo realizado indenização. Nesse momento, a medida teve os mesmos efeitos de uma expropriação, violando o investimento estrangeiro da Metalclad.

A empresa Conterin já havia conseguido, em 1990 e em 1993, as licenças federais e a permissão para a construção do Confinamento. A permissão de 1993 era oriunda do Instituto Nacional de Ecologia, organismo independente da Secretaria de Meio Ambiente, Recursos Naturais e Pesca. Ainda em 1993, após a permissão federal para a construção, a Metalclad iniciou contrato para a compra da CONTERIN e de suas permissões, com o fim de construir o confinamento de resíduos perigosos.

\footnotetext{
${ }^{24} \mathrm{O}$ tratamento igualitário é disposto da seguinte forma, no artigo 1105: “ 1. Cada una de las Partes otorgará a lasinversiones de losinversionistas de otra Parte, trato acorde conelderecho internacional, incluido trato justo y equitativo, así como protección y seguridad plenas. [...]”. TLCAN. Disponível em: $<$ http://www.nafta-sec-alena.org/sp/view.aspx? conID=590\& mtpiID=142\#A1105>. Acesso em: 10 fev. 2012.

${ }^{25} \mathrm{O}$ artigo 1110 estipula que "ninguna de las Partes podrá nacionalizar niexpropiar, directa o indirectamente, una inversión de uninversionista de otra Parte ensuterritorio, ni adoptar ninguna medida equivalente a laexpropiación o nacionalización de esainversión (expropiación), salvo que sea: (a) por causa de utilidad pública; (b) sobre bases no discriminatorias; (c) con apego al principio de legalidad y al artículo 1105(1); y (d) mediante indemnización conforme a lospárrafos 2 a 6.TLCAN. Disponível em: <http://www.nafta-sec-alena.org/ sp/view.aspx? conID=590\&mtpiID=142\#A1105>. Acesso em: 10 fev. 2012.
}

Pouco tempo depois, ainda em 1993, o governo estadual outorgou permissão estatal para o uso do solo para a construção do confinamento, com a condição de que o projeto se adaptasse às especificações e aos requerimentos técnicos indicados pelas autoridades correspondentes. Em agosto de 1993, o Instituto Nacional de Ecologia outorgou permissão federal para a operação do confinamento. Em setembro de 1993, foi finalizada a compra da CONTERIN pela Metalclad. ${ }^{26}$

Nesse sentido, a empresa Metalclad se sentiu prejudicada, pois já havia conseguido, tanto no âmbito federal, quanto estadual, licenças sobre a legalidade da localização e instalação do empreendimento, tendo passado pelos estudos exigidos e mesmo auditorias no local. O aterro foi construído, sendo finalizado em 1995. O problema foi quando o município exigiu outra licença para funcionamento, desconsiderando as licenças anteriores que a empresa havia recebido. ${ }^{27}$ Nesse momento, o governo municipal do México tomou medida que teve efeito de expropriação, ao privar a empresa de usufruir de seus investimentos.

O tribunal arbitral apreciou se houve violação ao tratamento justo e equitativo da empresa, de um lado, e, de outro lado, à natureza da medida do município, como uma medida com efeito de expropriação. A questão ambiental entra em cena no momento em que foi usada como justificativa pelo município para impedir a atividade da empresa.

Para explicar melhor, sobre o tratamento justo, a interpretação do tribunal analisa a responsabilidade do México diante da ação do município. O México é internacionalmente responsável pelos atos do município. Isso é regra não apenas do ICSID, mas do direito internacional, que determina que o direito interno não é justificativa para violação de obrigação internacional. ${ }^{28} \mathrm{~A}$ incongruência entre os diferentes níveis de governo, nesse sentido, acerca da permissão ou não das atividades acionou a responsabilidade internacional pelo dano que causou aos investimentos da empresa Metalclad. Assim entendeu o tribunal:

\footnotetext{
${ }^{26}$ ICSID. Tecmed x México. Disponível em: <http://ictsd.org/i/ news/4427/>. Acesso em: 10 fev. 2012.

${ }^{27}$ ICSID. Tecmed x México. Disponível em: <http://ictsd.org/i/ news/4427/>. Acesso em: 10 fev. 2012.

${ }^{28}$ Artigos 26 e 27 da Convenção de Viena sobre o Direito dos Tratados.
} 
74. El artículo 1105(1) del TLCAN dispone que "cada una de lãs Partes otorgará a lasinversiones de losinversionistas de otra Parte, trato acorde conelderecho internacional, incluido trato justo y equitativo, así como protección y seguridad plenas". Por lasrazonesabajoexpuestas, el Tribunal considera que no se leotorgó a lainversión de Metalcladun trato justo y equitativo acorde conelderecho internacional, y que México violo el artículo 1105(1) del TLCAN. ${ }^{29}$

A violação ao tratamento justo e equitativo ocorreu justamente porque a empresa tinha em mãos a certeza de que já havia corrido atrás de todas as licenças pedidas, assim como estudos de impacto ambiental, mas o município, ainda assim, exigiu-lhe outra permissão. Nos termos da decisão:

\section{$[\ldots]$}

79. Un punto central en este caso ha sido si, además de los mencionados permisos, se requeríaunpermiso municipal para laconstruccióndelconfinamiento de residuospeligrosos.

80. CuandoMetalcladinquirió, antes de comprar COTERIN, acerca de lanecesidad de permisosmunicipales, funcionariosoficialesleaseguraron que tenía todo lo que necesitaba para iniciar elproyectodelconfinamiento. De hecho, después de que Metalclad adquirió COTERIN, el gobierno federal prorrogó el permiso federal de construcción por dieciocho meses más. ${ }^{30}$

A incongruência constitui o dano ao investimento também porque a ação municipal, que passa a ser vista internacionalmente como a ação do México, foi fora de sua competência interna. In verbis:

81. Como expuso y confirmóel perito de Metalclad em legislación mexicana, las facultades del Municipio comprenden única mente el manejo de permisos de construcción, “...otorgar licencias y permisos de construcción, y participar enlacreación y administración de zonas de reservas ecológicas..." (Artículo 115 fracción V de laConstitución Mexicana) [...]. ${ }^{31}$

O tribunal considerou a medida do município como inadequada, ao referir-se a considerações de impacto ambiental, assim como sua medida de negar uma permissão por qualquer razão diferente de sua competência,

${ }^{29}$ ICSID. Tecmed x México. Disponível em: < http://ictsd.org/i/ news/4427/>. Acesso em: 10 fev. 2012.

${ }^{30}$ ICSID. Tecmed x México. Disponível em: < http://ictsd.org/i/ news/4427/>. Acesso em: 10 fev. 2012.

${ }^{31}$ ICSID. Tecmed x México. Disponível em: <http://ictsd.org/i/ news/4427/>. Acesso em: 10 fev. 2012. que seria a mera construção física do local. Nos termos da decisão:

\section{$[\ldots]$}

Por lo tanto, la negativa del Municipio a otorgar el permiso haciendo referencia a consideraciones de impacto ambiental sobre lo que era básicamenteunconfinamiento de disposición de residuos peligrosos, fueinadecuada, como lo fue también su negativa para otorgar um permiso por cualquier razón que no fuer aotra que alguna relacionada conlaconstrucción física o defectosdel sitio [...]. ${ }^{32}$

Segundo o tribunal, a questão ambiental não era justificativa para a medida do município, uma vez que já estava sendo apreciada em âmbito federal, pelo andamento do projeto de autorização da construção, e da construção propriamente dita:

98. El artículo 1114 del TLCAN, que permite que una Parte se asegure que las inversiones se efectúen tomando encuenta inquietudes em materia ambiental no afecta esta conclusión. La celebración del Convenio y elotorgamiento de los permisos federales muestran claramente que México estabas atis fechocon el hecho de que el proyecto era acorde con y tomaba encuenta inquietudes en materia ambiental. ${ }^{33}$

Diante dessas incongruências na condução do direito interno, as ações municipais violaram o tratamento justo e equitativo da empresa, nos termos do tribunal: "101. El Tribunal por lo tanto sostiene que Metalclad no fue tratado justa y equitativamente de acuerdo com el TLCAN y concede la reclamación relativa al artículo $1105{ }^{34}$

O segundo ponto analisado pelo tribunal consiste no enquadramento da medida do município como medida com efeitos de expropriação. Sobre esse ponto, é importante explicar que expropriação, perante o ICSID, significa tanto a confiscação da propriedade como a confiscação simulada, que gera os efeitos de privar o proprietário de usufruir de sua propriedade e investimentos. Nesse sentido, explica o tribunal:

[...] expropiación en el TLCAN incluye no sólo la confiscación de la propiedad de manera abierta, deliberada y conconocimiento de causa, tal como una confiscación directa o una transferência formal u obligatoria de títulos en favor

${ }^{32}$ ICSID. Tecmed x México. Disponível em: <http://ictsd.org/i/ news/4427/>. Acesso em: 10 fev. 2012.

${ }^{33}$ ICSID. Tecmed x México. Disponível em: <http://ictsd.org/i/ news/4427/>. Acesso em: 10 fev. 2012.

${ }^{34}$ ICSID. Tecmed x México. Disponível em: <http://ictsd.org/i/ news/4427/>. Acesso em: 10 fev. 2012. 
del Estado receptor, pero tambiém una interferencia disimulada o incidental del uso de la propiedad que tengaelefecto de privar, totalmente o en parte significativa, al propietario del uso o del beneficio económico que razonablemente se esperaría de la propiedad, aunque no necesariamente en beneficio obvio del Estado receptor. ${ }^{35}$

A incongruência interna também influencia a interpretação do enquadramento da medida como de efeitos de expropriação. A medida passou a equivaler a uma expropriação indireta, no momento em que o município ignorou as ações já tomadas na esfera federal. Uma vez reconhecida a medida como expropriação, o tribunal passou a analisar a quantificação da indenização devida. Para tanto, observou que a empresa ficou totalmente impossibilitada de exercer suas atividades, e como base de cálculo, os dados podem ser obtidos analisando-se o valor de mercado se fosse uma expropriação direta. $\mathrm{O}$ governo do México foi então condenado a pagar à Metalclad US $\$ 16,685,000.00 .{ }^{36}$

Esse caso também levanta os elementos jurídicos ressaltados no caso anterior: a relação entre ordens jurídicas distintas que fomenta a relativização do poder de regulamentação do Estado. Ilustra a complexidade da interação entre as lógicas da proteção de investimentos estrangeiros e a lógica de proteção do meio ambiente. Da mesma forma, demonstra a insuficiência da atuação estatal em vista da incoerência entre as ações nos diferentes níveis de governo, que causou o ilícito internacional à empresa estrangeira.

Basta perceber que, mais uma vez, em uma demanda que chegou ao ICSID por violação causada por medida de proteção ambiental, a lógica ambiental não prevaleceu perante a obrigação de proteção dos investimentos estrangeiros, nem diante da obrigação de indenizar. No caso, no momento em que causa efeitos de expropriação, é preciso o respeito à proteção dos investimentos estrangeiros.

A violação se deu porque o município, além ter agido fora de sua competência, ao negar a licença, agiu contra as ações estaduais e federais que já tinham autorizado o empreendimento. A divergência interna entre

${ }^{35}$ ICSID. Tecmed x México. Disponível em: <http://ictsd.org/i/ news/4427/>. Acesso em: 10 fev. 2012.

${ }^{36}$ ICSID. Tecmed x México. Disponível em: <http://ictsd.org/i/ news/4427/>. Acesso em: 10 fev. 2012. as ações do âmbito federal, estadual e municipal, que se constitui frustrando a expectativa dos investidores, pode ser vista como traços de uma fraca capacidade institucional do México em lidar com questões de ordem interna, tendo levado a demanda a um tribunal no ICSID.

Além disso, a decisão arbitral afeta a capacidade regulatória do município mexicano, diante da influência da decisão no âmbito nacional, decidindo se o município tinha ou não autoridade para impedir o funcionamento em se tratando matéria de lixo, tipicamente federal.

\subsection{0 caso Tecmed x México}

Em julho de 2000, a empresa espanhola Tecmed, Tecnicas Medio Ambientales S.A., em favor de sua subsidiária, a CYTRAR S.A, entrou contra o governo do México, no ICSID. Visava reclamar das medidas da Promotora Inmobiliaria del Ayuntamiento de Hermosillo, organismo público descentralizado municipal no estado de Sonora, México, no processo de adjudicação e transmissão de bens, por contrato de compra e venda, em 1996. O contrato dizia respeito à compra e venda dos bens para a operação do confinamento de resíduos perigosos em Las Víboras, Município de Hermosillo, no estado de Sonora. $\mathrm{O}$ centro da questão diz respeito à licença de uso desses bens, que foi negada à CYTRAR, no ano seguinte ao da venda dos bens, por motivos de proteção ambiental.

O Confinamento existia desde 1988 sobre um terreno adquirido pelo Estado de Sonora em Las Víboras, na jurisdição de Ayuntamiento de Hermosillo. A partir de dezembro de 1988, o estabelecimento tinha uma licença para o seu funcionamento, de 5 anos, prorrogáveis, emitida pela Secretaría de Desarrollo Urbano y Ecología. Durante esse tempo, o operador era também um Órgão público, o Parque Industrial de Hermosillo. Em seguida, os bens foram passados para a Promotoria e, em 1995, houve a licitação e extinção desse organismo público, cujos bens foram adquiridos pela Tecmed.

A Tecmed inicia suas atividades, mas começa a ter problemas com as renovações da licença, em dois momentos: primeiro, foi questionado pela Promotoria que as licenças não faziam parte da compra e venda; e, segundo, a renovação das licenças foi negada pelos riscos ambientais da atividade.

A respeito de as licenças estarem ou não entre os objetos do contrato de compra e venda, o tribunal do IC- 
SID entendeu que foram consideradas sim como partes, e que essa era a intenção das partes no momento da confecção do contrato. Outra questão da demanda foi a não renovação das autorizações em 1998. Após a aquisição do confinamento, em 1996, a empresa tinhaa autorização de operação, por parte da Prefeitura de Hermosillo (Pelo Instituto Nacional de Ecologia - INE), com vigência anual. Em 1997, a autorização foi prorrogada, mas, em 1998, o INE decidiu não renová-la, pois alegava que a empresa não vinha procedendo com as medidas de cautela com o meio ambiente e ainda ordenou que o confinamento fosse fechado definitivamente, justamente diante dos riscos ambientais em que incorria. ${ }^{37}$

A questão ambiental, acionada pelo poder de regulamentação do governo mexicano, foi considerada como violação ao investimento estrangeiro. Mais uma vez, entendeu-se que não importa o motivo das medidas, e sim os seus efeitos, que caracterizaram uma expropriação. O tribunal explica que, para identificar uma medida como expropriação, primeiro é necessária a privação da utilidade econômica do bem, que também determina se a expropriação é ou não é indenizável. Na letra da decisão:

Para establecer si la Resolución constituye medida equivalente a una expropiación bajo los términos del artículo 5(1) del Acuerdo, es necesario determinar, en primer término, si enrazón de laResoluciónla Demandante se vio privada, de manera radical, de la utilidad económica de su inversión, como si los derechos relativos a ésta-por ejemplo, la percepción o goce de los beneficios asociados con el Confinamiento o su explotación-hubiesen cesado. Es decir, si a raíz de actuación atribuible a la Demandada, los bienes en cuestión han perdido valor o utilidad para quien se beneficia de los mismos, y en que medida129. Esta determinación es importante, pues es una de las bases para distinguir, desde la perspectiva de un tribunal internacional, entre una medida regulatoria, expresión normal de la autoridad estatal en ejercicio del poder depolicía, que trae consigo una disminución de los bienes o derechos del particular, y una expropiación de facto, que priva de toda sustancia real a tales bienes o derechos. Al determinar el grado en que el inversor es privado de sus bienes o derechos, se determina también si esa privación es indemnizable o no; y al concluirse sobre este último punto, se concluye igualmente si la medida en cuestión constituyó o no una expropiación de facto.
A empresa demandou indenização por perdas e danos morais e materiais do governo mexicano, com um valor superior a US\$ 75 milhões. O tribunal arbitral considerou que a negação da renovação havia prejudicado de modo irreversível a operação do confinamento, considerando ainda que não houve proporcionalidade entre a sanção imposta pelo governo mexicano e as infrações cometidas pela empresa, uma vez que essas não comprometiam, segundo o tribunal, a integridade do meio ambiente. Por fim, condenou o México à indenização de US\$ 5,533 milhões à empresa e que essa devolvesse a propriedade ao governo mexicano. ${ }^{38}$

Nesse caso, também houve interferência na ação de regulamentação do Estado diante da interação entre a proteção ambiental e a proteção dos investimentos estrangeiros. Porque o tribunal considerou contraditório, incongruente e pouco transparente a ação do governo mexicano, talvez seja em razão de um devido processo legal adequado para o tratamento de casos semelhantes. Isso porque, segundo a decisão do tribunal, o governo foi condenado por ter atuado de forma desproporcional, em relação às infrações que verificou na operação, não tendo dado tempo à empresa para que esta se manifestasse.

\section{Elementos dos casos: pluralismo jurídico e efetividade da proteção do meio ambiente}

Dos elementos jurídicos importantes a serem destacados nos três casos, ressaltam-se, primeiro, a própria relação entre a proteção jurídica ambiental e a proteção jurídica aos investimentos estrangeiros. Já na simples existência dessa relação e nos possíveis choques entre essas duas ordens jurídicas distintas, é possível identificar um dos efeitos da globalização no direito, que é a influência dessa realidade pluralista no campo da teoria do direito, no qual ainda predomina o modelo estatal de entendimento do direito.

Em segundo lugar, também diante da relação meio ambiente e investimento estrangeiro, percebe-se a relativização do poder de regulamentação do Estado. Essa relativização é uma questão de efetividade, ou melhor, de se buscar entender motivos possíveis que levam a não efe-

\footnotetext{
${ }^{38}$ ICSID. Tecmed x México. Disponível em: <http://ictsd.org/i/ news/4427/>. Acesso em: 10 fev. 2012.
} 
tividade de algum objetivo tutelado juridicamente, que corresponde ao segundo ponto de análise.

Com tais considerações, segue a análise para primeiro estudar os impasses da existência de diferentes ordens jurídicas no entendimento do direito, verificando-se o necessário reconhecimento do pluralismo jurídico como ferramenta útil de estudo jurídico. Em segundo lugar, a análise seguirá para o estudo da efetividade da proteção ambiental e do desenvolvimento sustentável na relação com a proteção dos investimentos estrangeiros.

\subsection{A insuficiência da teoria estatal do direito e o pluralismo jurídico}

Os casos da Metalclad, Tecmed e Santa Elena permitem analisar alguns impasses da globalização no direito, ao ilustrarem a interação de diferentes ordens jurídicas. Ainda que a constatação de diferentes ordens não é em si novidade, o seu estudo é dificultado porque a teoria do direito ainda está consideravelmente 'viciada' em buscar compreender a realidade do direito pelas teorias estatais e essas não são suficientes. Não basta mais olhar apenas pelas fontes estatais, é preciso ampliar as ferramentas de estudo para um contexto pluralista, para outras vias de formação da norma, e repercussão entre elas.

Esclarecer esse impasse da adaptação é, então, pretender maior aproximação na aplicação da teoria à realidade. ${ }^{39}$ Procurando demonstrar esse raciocínio, primeiro se procura retratar alguns efeitos da globalização no direito, porque é preciso superar a teoria estatal do direito. Em seguida, seguem alguns dos elementos de uma abordagem pluralista.

\subsubsection{Alguns dos efeitos da globalização no direito}

Dentre os efeitos da globalização no direito, os casos Santa Elena, Metalclad e Tecmed permitem ilustrar a coexistência de ordens jurídicas distintas, fragmentação do direito e sua consequente descentralização do poder estatal. O direito, como forma de convenção entre as partes, mantém a sua função de esclarecimento das condutas a serem tomadas e, nesse sentido, expressa o seu papel de freio das forças da globalização em respeito aos diferentes

${ }^{39}$ EISENMANN, Charles. Quelques problèmes de méthodologie des définitions et des classifications en science juridique. In : ÉCRITS de théorie Du droit, de droit constitutionel et d'idées politiques. s, Paris: Edition Panthéon-Assa, 2002. p. 290-305. interesses das partes envolvidas. A globalização, por sua vez, dá ao direito novos objetos, novas demandas e novas razões para existir.

Globalização aqui é entendida em seu sentido geral, e em sua relação com a criação e aplicação do direito. Nesse sentido, o direito responde e se transforma face às mudanças sociais, no confronto entre forças sociais. Sendo um dispositivo de coordenação de condutas a fim de possibilitar uma existência em comum, é capaz de ser uma ferramenta importante para conter essas forças globalizantes. ${ }^{40}$ Os resultados, seja o de conter determinada força, seja o de fazê-la expandir e acarretar em um imperialismo, entretanto, dependem do modo como os atores utilizam as ferramentas jurídicas.

Seguindo esse raciocínio, os instrumentos normativos são utilizados de acordo com as demandas que vão emergindo na realidade. A fragmentação reflete a pluralidade de atores e objetos jurídicos. Inserem-se na produção do direito Estados, Organizações Internacionais, Organizações não Governamentais, lobistas, representantes privados diversos a tratar também dos mais variados assuntos. É, então, também a percepção das estruturas jurídicas, dos regimes jurídicos e esquemas em rede que pode ser vista como a realidade jurídica na cena internacional.

O resultado é a criatividade na conjugação de instrumentos políticos, jurídicos econômicos e outros dispositivos sociais, a exemplo do mercado de carbono, ${ }^{41}$ contratos internacionais,${ }^{42}$ certificações ambientais, ${ }^{43}$ ou-

${ }^{40}$ DELMAS-MARTY, Mireille. Les forces imaginantes $d u$ droit. Le relatif et l'universel. Éditions du seuil, p. 08.

${ }^{41}$ UNCOMMON GOODS: On Environmental Virtues And Voluntary Carbon Offsets. Harvard Law Review; Jun 2011, v. 123 Issue 8, p. 2065-2087, 23p. Disponível em: <http://web.ebscohost.com/ehost/pdfviewer/pdfviewer? vid $=7 \&$ hid $=110 \&$ sid $=$ d 30426 a $1-d 3$ b $0-492 \mathrm{e}-$ ab $91-$ 23de84b7239d\%40sessionmgr114>. Acesso em: 26 jul. 2011.

${ }^{42}$ Por exemplo, no campo dos biocombustíveis: LIMA, Gabriela Garcia Batista. O caso do bioetanol brasileiro: a proteção ambiental e o desenvolvimento sustentável pela atuação de empresas privadas. In: ENCONTRO NACIONAL DO CONPEDI, 19., 2010, Fortaleza. Anais... Fortaleza, 2010.

${ }^{43}$ BLANC, David. L'Éco-labellisation et l'éco-certification. In: MALJEAN-DUBOIS, Sandrine. L'outil économique en droit international et européen de l'environement. Paris: La documentation française, 2002. p. 365. 
tros instrumentos econômicos no mercado, ${ }^{44}$ governança corporativa, ${ }^{45}$ códigos éticos empresariais, sistemas regulatórios globais ${ }^{46}$ e a própria arbitragem. São todos exemplos de ações que caracterizam a atualidade jurídica, ultrapassam o campo estatal e estão presentes no campo privado de atuação.

A criação do direito no campo da globalização reflete a especialização exigida por cada objeto, que leva a criar os diferentes regimes jurídicos: áreas como o direito internacional ambiental, direito internacional comercial, proteção dos direitos humanos etc. ${ }^{47}$ Ademais, as normas privadas e a própria arbitragem privada são também frutos do aumento das relações jurídicas e de formas de relações jurídicas diante da globalização, e, em especial, da exigência de especialização no campo jurídico para lidar com os objetos, agora normatizados.

De um lado, resta ao direito sua função mais antiga de regular uma relação entre determinados atores. De outro lado, no pluralismo jurídico, é preciso ter em mente o estudo da repercussão entre essas ordens, uma visão de relação entre sistemas jurídicos distintos. $\mathrm{Na}$ interação entre relações sociais, normas jurídicas podem existir. Da mesma forma, na interação entre essas diferentes ordens jurídicas, conflitos podem existir, repercutindo na efetividade uma da outra.

Assim, a fragmentação possibilita instrumentalizar também a análise da coexistência desses diferentes regimes, as pontes, influências, interações entre eles. ${ }^{48}$ É a superação do formalismo jurídico pelas diferentes exigências de eficácia e efetividade. ${ }^{49}$ Nesse sentido, a globa-

${ }^{44}$ MALJEAN-DUBOIS, Sandrine. Le recours à L'outil économique: un habit neuf pour les politiques environnementales ? In: MALJEAN-DUBOIS, Sandrine (Org.). L'outil économique en droit international et européen de l'environement. Paris: La documentation française, 2002. p. 10.

${ }^{45}$ ANDRADE, Adriana; ROSSETTI, José Paschoal. Governança corporativa: fundamentos, desenvolvimento e tendências. São Paulo: Atlas, 2004. p. 20.

${ }^{46}$ CASSESSE, Sabino. Administrative Law without the State. The Challenge of global regulation. p. 671.

${ }^{47}$ KOSKENNIEMI, Martti. The politics of international Law 20 years later. The European Journal of International Law, v. 20, n. 1, p. 7-19, , 2009.

48 TEUBNER, Gunter. "And if I by Beelzebub cast out Devils, ...": An Essay on the Diabolics of Network Failure. SPECIAL ISSUE: THE LAW OF THE NETWORK SOCIETY A TRIBUTE TO KARL-HEINZ LADEUR. German Law Journal v. 10 n. 4, p. 115-136.

${ }^{49}$ MARAIS, Bertrand du. Droit Public de La régulation économique. Presses de Sicences PO etDalloz, 2004. p. 31. lização é relevante para o direito porque suas forças, como os mercados ou posicionamento de grandes corporações, influenciam o controle de políticas nacionais e as mudanças na forma de regulação, o que também gera problemas na produção do direito (não mais somente estatal). ${ }^{50}$

Nessa perspectiva, o direito institucionaliza a ponte e transferência de poder dos atores estatais para os atores econômicos, mas, por outro lado, cria a oportunidade de constituição de setores autônomos na sociedade civil. ${ }^{51}$ Esse entendimento corresponde justamente a um dos elementos da relação entre globalização e o direito.

Nesse sentido, o estudo do direito começa a exigir a superação paradigmática do modelo estatal face aos efeitos da globalização. Superação dos instrumentos de um direito marcado pela relação estado-nação, intervenção e regulamentação, hierarquia na tomada de decisão, que, então, tornam-se ineficazes. Nesse sentido, a transnacionalização dos mercados de insumos, produção, capitais etc., que não é limitada ao território nacional, torna as fronteiras burocráticas ineficazes, e o modelo estatal de direito, insuficiente. ${ }^{52}$

Torna-se possível identificar o que parece ser o conceito chave para a compreensão dessa crise jurídica: a fragilização da autoridade estatal ante à coexistência de outras autoridades capazes de implementar suas ordens. Dessa forma, a coexistência de diferentes ordens jurídicas, além da estatal. Diante dessa realidade, é preciso uma superação do modelo estatal no estudo do direito, argumento a ser esclarecido a seguir.

\subsubsection{Da crise no modelo estatal na explicação e no estudo do direito}

Limitando-se a análise para esse breve estudo, a partir do século XX, destacam-se alguns elementos da teoria jurídica a fim de demonstrar como o modo de entender o direito parece chegar a uma exaustão paradig-

${ }^{50}$ TEUBNER, Gunter. Global Private Regimes: Neo-spontaneus Law and dual constitution of autonomus sectors in world society? In: KARL-HEINZ, Ladeur (Ed.). Globalization and Public Governance, Ashgate, Aldershot. 2004. p. 71-87.

${ }^{51}$ TEUBNER, Gunter. Global Private Regimes: Neo-spontaneus Law and dual constitution of autonomus sectors in world society? In: KARL-HEINZ, Ladeur (Ed.). Globalization and Public Governance, Ashgate, Aldershot. 2004. p. 71-87.

${ }^{52}$ FARIA, José Eduardo. O direito na economia globalizada. São Paulo: Malheiros Editores, 2002. p. 13. 
mática.$^{53}$ Não se pretende fazer aqui um roteiro histórico sobre o direito, destacam-se apenas alguns aspectos do fundamento e da validade do direito, de um lado, e, de outro lado, o entendimento das principais explicações sobre as relações entre direito interno e direito internacional. Além disso, a crítica segue no sentido de que essa superação não deve ser entendida apenas em nível teórico, mas também do ensino jurídico, que ainda limita em muito o estudo do direito ao modelo estatal.

O fundamento do direito, seja do direito interno, seja do direito internacional, é tradicionalmente vinculado ao Estado. Assim permanece, seja dentro de um conhecimento objetivista, seja pelo voluntarismo. É possível iniciar essa abordagem, lembrando uma das teorias que mais influenciou o ensino jurídico mesmo nos dias de hoje, a compreensão de direito para Kelsen e o seu entendimento sobre a relação entre direito interno e direito internacional. E, a partir daí, observar as principais características da relação entre direito e Estado, assim como na contraposição entre os objetivistas e os voluntaristas.

Kelsen compreende o direito pelo modo como entende a natureza do Estado. O Estado tem a natureza de força, e os indivíduos são os seus sujeitos. Como força, o Estado é essencialmente vontade, mas uma vontade distinta da dos indivíduos, é mais que sua soma, lhe é superior. ${ }^{54} \mathrm{O}$ Estado, então, visando à orientação da conduta $\mathrm{e}$ vontade humana na sociedade, opera a sua ordem, a estatal. Esta, por sua vez, se difere de outras ordens sociais diante do seu teor vinculante, garantida por um sistema consideravelmente efetivo, que é o direito. Nesse sentido, para Kelsen, ordem estatal e ordem jurídica chegam a ser sinônimos:

\footnotetext{
«État et droit - Il en résulte que l'appareil de contrainte, ou l'on voit généralement la caractéristique de l'État, est identique à l'ordre juridique. Les règles qui constituent l'ordre étatique sont les régles du droit. La norme juridique est la règle en vertu de laquelle s'opère l'imputation à l'État, qui, en tant que sujet des actes étatiques, $n$ 'est que la personnification de l'ordre juridique. ${ }^{55}$
}

${ }^{53}$ FARIA, José Eduardo. O direito na economia globalizada. São Paulo: Malheiros Editores, 2002. p. 39.

${ }^{54}$ KELSEN, Hans. Les rapports de systême entre le droit interne et le droit international public. The Hague Academy of International Law. p. 244.

${ }^{55}$ KELSEN, Hans. Les rapports de systême entre le droit interne et le droit international public. The Hague Academy of International Law. p. 242-243.
Essa função do direito, de garantir o aparelho Estatal e conduzir a conduta humana, é o que justifica a sua existência. O direito é, então, uma técnica de limitação da vontade. É composto de normas primárias (obrigação) e secundárias (sanção) de apresentação e limitação da vontade e sua sanção. ${ }^{56}$ Nesse sentido, se a conduta humana não precisasse ser orientada, não haveria porque instituir uma ordem jurídica.

Nesse raciocínio, outro elemento constitutivo comumente atrelado ao conceito de direito, e que o diferencia de outras normas sociais, é o modo como vincula. A composição de normas primárias e secundária não é apenas uma convenção entre as partes, mas um acordo que, se violado, incorrerá em alguma sanção. Seguindo o ensinamento de Hart, entender a norma jurídica assim é classificá-la como um imperativo sancionador. ${ }^{57}$

Tal modelo, então, trás o conceito formal e material de Estado que influencia diretamente para um elemento formal no estabelecimento de qual seria a fonte de direito legítima: o Estado. O conceito formal do Estado inclui a totalidade do sistema de direito ou fatos jurídicos, e o conceito material inclui regras e atos jurídicos realizados por determinada categoria de indivíduos. ${ }^{58}$ Mas, isso não significa dar validade ao direito, é apenas condição para que se produzam normas jurídicas: a necessidade de orientação da conduta humana.

Acerca da validade do direito, no entendimento de Kelsen, encontra-se fundamentada uma norma hipotética fundamental, que lhe garante validade. Nesse sentido, é o próprio direito que lhe dá validade. ${ }^{59}$ É o que caracteriza entendimentos, nesse sentido, como sendo objetivistas, em contraposição com os voluntaristas, que relacionam a validade do direito com a vontade dos seus declarantes.

Verdross afirma, também nesse sentido, que a fonte do direito é a ordem jurídica e não a vontade dos seus declarantes. Considerando impossível estabelecer a fonte

${ }^{56}$ KELSEN, Hans. Teoría pura del derecho, Introdución a la ciência delderecho. Buenos Aires: Eudeba Editorial Universitária de Buenos Aires, 1960. p. 73-74.

${ }^{57}$ HART, H.L.A. O conceito de direito. São Paulo: WMF M. Fontes, 2009. p. 281.

${ }^{58}$ KELSEN, Hans. Les rapports de systême entre le droit interne et le droit international public. The Hague Academy of International Law. p. 244.

${ }^{59}$ KELSEN, Hans. Teoría pura del derecho, Introdución a la ciência delderecho. Buenos Aires: Eudeba Editorial Universitária de Buenos Aires, 1960. p. 73-74. 
do direito internacional tão somente nas Constituições nacionais, se o Estado mudar sua vontade e constituição, o direito internacional pode ainda permanecer. ${ }^{60}$ Nesse raciocínio, é possível observar que, por mais que a linha entre Estado e direito seja sutil, existe certa autonomia entre os dois, já que, como dito, para os objetivistas, a validade do direito encontra-se no sistema jurídico, e não na vontade dos Estados.

De modo diverso, a abordagem voluntarista relaciona a validade do direito com a vontade dos Estados, sendo esta, então, a principal fonte jurídica. Nesse sentido, segue Triepel, para quem uma regra jurídica é o conteúdo de uma vontade superior às vontades individuais. A fonte do direito é a vontade do Estado, seja perante o direito nacional, seja diante do direito internacional. ${ }^{61}$ Nesse raciocínio, o direito internacional somente pode ser produzido por sujeitos de direito internacional, para ele, o Estado ${ }^{62}$.

\footnotetext{
${ }^{60}$ Explica Verdross que a noção da humanidade como unidade vem principalmente da Idade Média e da influência do cristianismo nessa época e perdura nas discussões sobre o fundamento do direito que se sucedem. Além do elemento unidade, entra em cena a perspectiva democrática da comunidade internacional, em que toda vontade é soberana, e a comunidade internacional é criada pelo consentimento dos membros da comunidade internacional. Mas o consentimento não basta para criar uma obrigação, esta só se cria com base em outra norma jurídica. Interessante notar como Verdross ilustra alguns momentos distintos nas explicações do fundamento e validade do direito. Grosso modo, dizem respeito à captação da ideia de unidade e do direito, aplicada a todos os fundamentos de autolimitação, em que cada Estado é responsável pelos seus atos. $\mathrm{O}$ autor passa pelos principais fundamentos, do direito natural ao positivismo jurídico, e pelo estudo de algumas perspectivas chaves sobre a questão, desde Grotius, Triepel, Hegel e Kelsen, dentre outros. A busca pela legitimação da origem do direito internacional perpassa, seja pela explicação universalista naturalista, seja pela explicação positivista, em torno da ideia que o direito emana do Estado e segue para a justificativa da sua obrigatoriedade, interna e externamente. VERDROSS, Alfred. Le fondement du droit international. The Hague Academy of International Law. p. 251.

${ }^{61}$ Para um melhor entendimento das origens do direito internacional: VERDROSS, Alfred. Le fondement du droit international. The Hague Academy of International Law. Hague Academy of International Law., e DINH, NguyenQuoc; DAILLIER, Patrick; PELLET, Alain. Direito internacional público. 2. ed. Tradução Vítor Marques Coelho. Fundação CalousteGuldenkian, 2003.

${ }^{62} \mathrm{O}$ indivíduo, no campo do direito internacional, só poderia aparecer como objeto de direitos e deveres internacionais e, da mesma forma, os atos produzidos pelos atores internos também seriam direito internacional. TRIEPEL, Carl Heinrich. Les rapports entre le droit interne et le droit international. ThaHagueAcademyofinternational. p. 81 .
}

Nesse sentido, sobre a validade do direito, de um lado, tem-se o entendimento objetivista que a vincula dentro do próprio direito, ainda que este seja o mesmo que ordem estatal; de outro lado, o voluntarismo, em que a fonte do direito está na vontade dos Estados. O que essas teorias não conseguem responder, como já indagou Hart, é como saber que os Estados só podem ser limitados por obrigações que eles mesmos impuseram. ${ }^{63}$

Eis um ponto de necessária superação diante de casos como Metalclad, Tecmed e Santa Elena. Neles, a vontade dos declarantes, não somente Estados, foi elemento constituinte da validade do direito entre as partes, já que a arbitragem só é válida mediante consentimento prévio, e a partir daí, torna-se obrigatória, vinculando o direito nacional envolvido.

Por esses casos, o elemento - Estado -, como constitutivo para a produção do direito, é relativizado e tem sua relativização institucionalizada, seja pelo ICSID, seja pela aceitação dessas normas e decisões arbitrais, por parte dos Estados. Do ponto de vista teórico, o direito já não tem a pretendida racionalidade centralizada no Estado, já que a ordem estatal resta superada "pelas ordens que lhe ditam sua lei". ${ }^{64}$

É certo que as demandas das empresas encontram-se amparadas por tratado em que os Estados envolvidos são partes. Nesse sentido, poderia se construir o raciocínio de que as normas jurídicas ainda são produzidas no campo Estatal. Entretanto, os casos apontam para mais que isso, demonstram certa submissão na ação jurídica e administrativa do Estado no que diz respeito ao seu direito nacional, em relação, não apenas ao tratado (NAFTA), mas aos interesses da empresa. Se a aplicação do seu direito nacional constituir violação a investimento estrangeiro, o Estado será chamado para mudar o seu comportamento, chegando ao ponto de ter que pagar indenizações a atores fora do seu Estado, para fazer cumprir a lei dentro do seu território.

Seguindo esse raciocínio, o Estado indica um padrão, e a soberania indica um poder de mando incontestável. São formas padronizadas de agir, que não funcio-

${ }^{63}$ HART, H.L.A. O conceito de direito. São Paulo: WMF M. Fontes, 2009. p. 289.

${ }^{64}$ LIBCHABER, Rémy. L'impossible rationalité de l'ordre juridique. "L'impossible rationalité de l'ordre juridique », Mél. Oppetit, à paraître. p. 505-528, p. 505. 
nam em um campo sem padrão certo, sem hierarquia padronizada, com forças de poder maiores e mais expressivas que o Estado que, então, perde sua unidade, centralidade e exclusividade diante de novos centros de poder. ${ }^{65}$

É pelo consentimento das partes, pública ou privadas, e não somente mais do Estado, que o direito é criado, inclusive, com caráter obrigatório. Os casos chamam atenção ainda para o fato de que essa relativização do papel estatal na produção normativa não tem limites nem a respeito da matéria, uma vez que meio ambiente é matéria antes considerada tipicamente estatal.

Compreendida essa questão acerca dos pontos de superação no fundamento e na validade do direito, outro aspecto a ser ressaltado diz respeito às relações entre direito interno e direito internacional. A teoria do direito seguiu ainda buscando preservar o Estado como ponto constitutivo do direito, diante da necessidade de impor a sua obrigatoriedade. Assim, seguiu-se também nas discussões sobre o monismo e o dualismo. Sem a pretensão de aprofundar a análise nessas teorias, se destacam aqui por visarem defender sua perspectiva à obrigatoriedade do direito internacional.

O breve entendimento dessas teorias apresenta pistas interessantes sobre a dificuldade de lidar com um conceito para o direito internacional, diante do apego ao Estado e à noção de obrigação da norma. Superar essa dificuldade é aproximar do conceito mais primário de direito, que pode facilitar a análise jurídica na presença do direito internacional.

No que diz respeito às teorias, a maior diferença entre elas é considerar direito interno e direito internacional ou como um sistema só ou como sistemas jurídicos distintos, sempre ligados ao Estado.

A teoria representante clássica do dualismo consiste na teoria de Triepel. Esta explica que são sistemas para reger relações distintas. Internamente, é o Estado perante seus cidadãos e, externamente, é o Estado frente a outros Estados. ${ }^{66} \mathrm{O}$ direito internacional não é uma ordem apenas, mas várias, como já chamou atenção Ver-

${ }^{65}$ FARIA, José Eduardo. O direito na economia globalizada. São Paulo: Malheiros Editores, 2002. p. 22-23.

${ }^{66}$ TRIEPEL, Carl Heinrich. Les rapports entre le droit interne et le droit international. ThaHagueAcademyofinternational. p. 81 . dross, ao analisar a questão. ${ }^{67}$ Essa pluralidade no dualismo, entretanto, ainda corre com a limitação de que o conceito de ordem jurídica, também para Triepel, está diretamente relacionado ao Estado, sujeito de direito internacional, condição sinequa non para a validade de sua declaração de vontade como fonte de norma jurídica.

O monismo pode seguir para duas vias que Verdross esclarece no seguinte sentido: na primazia do direito nacional, eis que a vontade do Estado e sua ordem estatal deveriam ser respeitadas por todos os outros Estados; na primazia do direito internacional em que, uma vez que este entrar em contradição com o direito nacional, aquele prevalecerá. Buscando relativizar a conclusão de uma resposta única, o autor diz abandonar a primazia do direito nacional e conclui que em cada caso se buscará pelo direito aplicável, seja nacional, seja internacional. ${ }^{68}$

Dentre vários motivos que Verdross expõe para negar o caráter absoluto da primazia do direito nacional, assim como defender o monismo, merece destaque a caracterização do direito nacional como meros fatos. Não consiste, nesse sentido, um diálogo entre normas jurídicas: se o direito nacional viola alguma obrigação de direito internacional, causa ilícito internacional. Defende tal posição por sua análise perante as discussões de direito internacionais, entendimento que remonta, pelo menos segundo a análise do autor, desde 1926, à Corte Permanente de justiça internacional. ${ }^{69}$

É evidente que a discussão ainda gira em torno do Estado, isso já resta compreendido até esse ponto da análise. Entre o monismo e o dualismo, o que está em jogo é saber sobre a obrigatoriedade do direito para os Estados e a sua relação com os direitos nacionais. É como a obrigatoriedade funciona, é o ponto-chave para a compreensão do direito internacional e que pode servir de ponte à superação do modelo estatal de estudo do direito.

${ }^{67}$ VERDROSS, Alfred. Le fondement du droit international. The Hague Academy of International Law. p. 289.

${ }^{68}$ VERDROSS, Alfred. Le fondement du droit international. The Hague Academy of International Law. p. 270.

${ }_{99}$ "Cette pratique constante est couronnée maintenant par la décision de la Cour permanente de Justice Internationale du 25 juillet 1926, relative à certains intérêts allemands en HauteSilésie et qui dit expressément : "En regard du droit international...les lois nationales sont des simples faits... au même titre que les décisions judiciaries au les mesures administratives." "VERDROSS, Alfred. Le fondement du droit international. The Hague Academy of International Law. p. 270. 
A obrigatoriedade do direito internacional se torna tema importante para entendê-lo como direito. A dificuldade está em analisar o direito internacional tendo em mente o conceito de direito tradicional, este construído diretamente relacionado com o Estado. Porque se toma ponto de partida um conceito estatal de direito, é possível causar enorme confusão ao se buscar analisar o direito internacional, precisando de justificativas outras que não o caráter vinculante da norma, para o conceito do direito internacional. ${ }^{70}$

Hart já havia chamado atenção para a diferença de contexto entre o direito nacional e o direito internacional. Ressaltou que o direito internacional simplesmente possui uma realidade diferente do direito nacional, diante da ausência de instituiçõos estatais, dos diferentes graus de interdependência dos Estados e da presença de uma pressão generalizada no cenário internacional, com retaliações e represálias. No "pano de fundo" do modo de aplicação do direito, diante da realidade distinta, o direito internacional não precisa de um conceito tão repressivo de sanção quanto o direito nacional, são modos distintos de se trabalhar com a obrigatoriedade da norma, cada um adaptado ao seu contexto. ${ }^{71}$

A partir daí, é possível observar que o extremo apego das teorias jurídicas ao conceito de Estado para a explicação do direito se dá porque existe uma necessidade de explicar o caráter de obrigatoriedade para caracterizar uma norma como jurídica. Superar essa dificuldade é enxugar o conceito de direito para a noção de simples pacto entre as partes, obrigando suas condutas por meio de mecanismos normativos.

${ }^{70}$ HART, H.L.A. O conceito de direito. São Paulo: WMF M. Fontes, 2009. p. 280.

${ }^{71}$ Nesse raciocínio, Hart aproxima o conceito do direito internacional ao seu conceito de norma primária de obrigação. As normas primárias e secundárias em Hart compõem o conceito de direito se entendido esse como imputação sancionatória, ou seja, seguindo-se esse conceito de direito, exige-se a presença do Estado, constituição de normas primárias (que identificam uma necessidade ou obrigação) e normas secundárias (que dispõem sobre o uso oficial da força como sanção à violação das primeiras. $\mathrm{O}$ direito internacional não apresenta as características necessárias para um conceito tão fechado de direito como esse estatal, entretanto, não significa que não seja direito, é o que Hart chama atenção em seu capítulo dedicado ao direito internacional. HART, H.L.A. O conceito de direito. São Paulo: WMF M. Fontes, 2009. p. 306.
Para além da constatação de que são realidades jurídicas distintas como expôs Hart, o direito internacional segue a dinâmica das relações internacionais e, portanto, é afetado pelas suas transformações, inclusive nas transformações de seus atores. Já resta mais que claro que os Estados não são mais os únicos sujeitos do direito internacional e não apenas organizações e blocos internacionais estão se constituindo, mas outros atores, como empresas, ganham espaço e utilizam-se dos instrumentos jurídicos que lhe são disponíveis.

Seguindo esse raciocínio, um conceito de direito mais simples que o conceito estatal permite facilitar a análise jurídica quando os casos a serem analisados não se enquadram nessas perspectivas estatais de explicação do direito, como os já apresentados, Santa Elena, Tecmed e Metalclad.

A superação teórica do modelo estatal, nesse sentido, foi apresentada aqui na necessidade de se trabalhar com o direito também fora de sua concepção exclusivamente estatal, assim como perceber que a obrigatoriedade da norma não precisa estar vinculada ao Estado. $\mathrm{O}$ direito é visto então em situações ainda mais simples, que é o uso de instrumentos normativos para pactuar algo entre partes.

Além disso, o modelo estatal de entendimento do direito, até hoje, é de grande influência também no ensino do direito. Tal modelo não perde seu lugar ou importância, até mesmo porque é preciso conhecer a ordem estatal para operá-la. A crítica é a limitação do objeto de estudo daqueles que estudam o Direito, como sendo a ordem estatal a única ordem jurídica válida. Isso porque, diante de sua pretensão científica de compreensão dos fatos, a teoria influencia a forma como os operadores do direito buscarão compreender tal realidade. Uma teoria inadequada trará dificuldades para aquele que a utiliza. Tal limitação ainda é presente no ensino jurídico por sua reprodução cega e afeta na própria qualidade da faculdade, em que o jurista pode não sair preparado para lidar com a realidade.

Esse impasse, vale ressaltar, também não é novo. A insuficiência do modelo do direito, como a ordem estatal, vem sendo complementada por diferentes ferramentas da sociologia jurídica, como análises econômicas do direito, internacionalização dos direitos, entre outros. Cada vez mais se chama atenção para outros elementos no estudo do direito. 
Para entender melhor tal crítica, destacam-se, a seguir, breves considerações sobre a pretensão científica da teoria em querer explicar a realidade com um modelo demasiado simples, o direito como a ordem estatal. Em seguida, chamou-se atenção para o fato de que estender o objeto do direito para toda influência não jurídica pode ser igualmente perigoso e inviável. Como possível saída desse impasse, destaca-se a simples decisão epistemológica do estudante de estabelecer convencionalmente o que e como irá estudar.

Iniciando-se a abordagem aqui com a teoria de Kelsen, seus estudos foram de grande influência porque definiu o objeto de estudo do direito como a norma jurídica. Buscando um caráter científico para a ciência jurídica, a teoria pura do direito combate o direito natural e a sociologia.

Contra o direito natural, a limitação do objeto do direito busca a objetividade da ciência pela tarefa de conhecer a realidade, e não de avaliá-la, esta pertencendo ao campo dos valores. E, contra a sociologia, a teoria pura de Kelsen visava distinguir o objeto jurídico como o dever ser, do objeto social, o ser. ${ }^{72}$

Rémy Libchaber esclarece o possível oportunismo na doutrina Kelseniana que liga a ordem jurídica à ordem estatal, procurando legitimar a teoria pura do direito como a racionalidade jurídica adequada. O Estado, então, tem o porte ideológico para controlar as desordens no direito e convergi-las a seu critério. ${ }^{73}$ É o Estado tentando ditar as regras que irão conduzir a realidade de seus cidadãos e legitimar tal atitude.

Nesse sentido, nada melhor que uma explicação teórica visando racionalizar os fatos que interpretam a realidade como forma de convencer que o seu argumento é o certo por um suporte teórico racional. Nesse caso, a ação do Estado, por meio do direito, é explicada por uma teoria do direito estatal. O modelo não apenas define o direito, mas orienta a organização da sua constituição, assim como fornece os elementos para o seu estudo.

\footnotetext{
${ }^{72}$ Para melhor análise sobre o assunto: BOBBIO, Norberto. Direito e poder. Tradução Nilson Moulin. São Paulo: Unesp, 2008. p.24.

${ }^{73}$ LIBCHABER, Rémy. L'impossible rationalité de l'ordre juridique. "L'impossible rationalité de l'ordre juridique », Mél. Oppetit, à paraître. p. 516.
}

No direito, as teorias gerais possuem uma pretensão científica de transformar o conjunto de fenômenos jurídicos que elencam (leis, decisões, jurisprudências etc.) em um sistema supostamente ordenado e coerente, que tem, por efeito, racionalizar o Direito. ${ }^{74}$ Nesse sentido, ainda que tenha pretendido uma ciência, as teorias acabam por prescrever o seu modelo e essa reprodução pode ser perigosa, limitando a análise dos objetos. ${ }^{75} \mathrm{O}$ que ocorre é que, na medida em que tais arranjos teóricos são ensinados e reproduzidos ${ }^{76}$ nas faculdades jurídicas e nos entendimentos acerca do que é o direito, perpetua-se o seu raciocínio sobre como se deve entender a realidade jurídica e se trabalhar perante ela.

Ou seja, as teorias estatais querem refletir seus objetivos como se fossem da vida real, quando dizem racionalizar um conjunto de fenômenos. Visam não apenas explicar os fenômenos jurídicos, mas, ainda, o modo correto de conduzi-los. Como consequência, são as teorias também a própria construção de um argumento para o convencimento do jeito certo de interpretação de uma dada realidade.

Nesse mesmo sentido, para além de uma vertente simplesmente didática ou pedagógica, as teorias do direito têm a pretensão de regrar cientificamente os conflitos de interesse. Adquirem uma espécie de autoridade, inter-

\footnotetext{
${ }^{74}$ Sébastien Pimont desenvolve um raciocínio crítico acerca do papel das teorias gerais, ao parecerem estar em "desuso", ao se buscar sua compatibilidade com a prática. Realiza sua crítica tendo por exemplos, questões contratuais. Demonstra que, embora possuam seu papel no ensino e no entendimento do direito, porque as teorias tomam a atenção para si, sua utilização bloqueia a criação de novos conhecimentos, de forma que são os excessos, os perigos da teoria, e não a teoria em si. PIMONT, Sébastien. Peut-on réduire Le droit em théories générales ? Exemples en droit du contrat. Revue trimestrelle de droit civil, Paris, p. 417-432, juillet-septembre 2009.

${ }^{75}$ Sigo o raciocínio de Bobbio sobre Kelsen, quando analisa que o que Kelsen designa para a ciência do Direito não deriva de uma descrição do que os juristas fazem em geral, mas é uma tarefa que o próprio Kelsen designa para o jurista e, assim, não tanto uma descrição como uma involuntária prescrição do modo pelo qual o bom jurista deveria se comportar para corresponder a um modelo ideal, de modo que uma ciência neutra do Direito é obtida com o preço de uma metaciência ideologizada. BOBBIO, Norberto. Direito e poder. Tradução Nilson Moulin. São Paulo: Unesp, 2008. p. 13.

${ }^{76}$ Reproduz-se o entendimento diante do poder simbólico de construção do que deveria ser a realidade a ser trabalhada. Segundo Pierre Bourdeau, o poder simbólico é um poder de construção da realidade que tende a estabelecer uma ordem: o sentido imediato do mundo (social). BOURDIEU, Pierre. $O$ pode simbólico. Rio de Janeiro: Bertand Brasil, 1989. p. 09.
} 
pretando um conjunto de fenômenos, pretendendo-se esclarecer verdades sobre esses fenômenos, o que sugere que existia uma realidade jurídica objetiva, a ser revelada teoricamente. ${ }^{77}$

Todavia, as teorias estatais de entendimento do direito não são de todo inúteis. Seja para a compreensão do direito, seja como instrumento para um determinado argumento jurídico, o perigo está no conformismo a tais arranjos, direcionando a atenção dos juristas para uma forma específica de compreensão, a forma que racionalizou. ${ }^{78}$ Nesse sentido, monopolizam a atenção, bloqueando a criação de novos conhecimentos, de forma que é na sua rigidez o problema, e não na teoria em si ou na sua utilidade para o ensino do direito.

O fato é que essas teorias estatais já não correspondem à realidade jurídica, ${ }^{79}$ de forma que, do ponto de vista epistemológico, limitar o direito à ordem estatal, atualmente, é reduzir demais o âmbito de estudo do direito. Por outro lado, dizer que o objeto da teoria jurídica deve também abranger outras influências sociais, para o seu estudo, é cair na cilada de tornar demasiado amplo o campo de estudo jurídico. E, visto assim de forma geral, é possível, inclusive, afirmar a inviabilidade de tal amplificação. Então, para ambos os lados, é inviável o estudo do direito, um é restrito demais, e o outro é amplo demais.

Talvez para evitar esse impasse de inviabilidade, é possível se perguntar se é realmente necessária a definição do objeto, para o estudo do direito. Talvez seja possível apenas deixar claro exatamente "o que" e "em que perspectiva" estamos estudando a realidade jurídica. Desse modo, a definição do objeto é uma convenção, o que e como está propondo analisar. Tal descrição pode, ora, recair sobre um modelo estatal, e ora não.

\footnotetext{
77 PIMONT, Sébastien. Peut-on réduire Le droit em théories générales ? Exemples en droit du contrat. Revue trimestrelle de droit civil, Paris, p. 417-432, juillet-septembre 2009.

${ }^{78}$ PIMONT, Sébastien. Peut-on réduire Le droit em théories générales ? Exemples en droit du contrat. Revue trimestrelle de droit civil, Paris, p. 417-432, juillet-septembre 2009.

${ }^{79}$ Waline faz um estudo entre o campo administrativo de atuação estatal e os ensinos em direito administrativo, demonstrando como diferentes definições doutrinárias, mesmo tendo seu lugar na ciência jurídica, não influenciam uma evolução na jurisprudência do conselho do Estado, esta apegada a realidades concretas. WALINE, Marcel. Empirisme et conceptualism dans la méthode juridique : faut-il tuer les catégories juridiques? Mélanges Jean Badin, p. 359-371.
}

Nesse raciocínio, é possível esclarecer que não são as teorias estatais em si, mas é a inflexibilidade no seu uso, principalmente para a análise do direito internacional, e o vício no ensino do direito, com a sua reprodução cega e rígida. Se a teoria é insuficiente, o seu estudo é prejudicado, incompleto ou mesmo pode ser visto como algo surreal. Entendida essa superação do paradigma estatal, a análise segue para um estudo mais a fundo do pluralismo jurídico que consiste justamente nessa extensão do olhar jurídico para além do Estado, como segue.

\subsubsection{O pluralismo jurídico}

O pluralismo jurídico, como instrumento de análise, apresenta ferramentas interessantes para o estudo do direito, na medida em que não se limita ao Estado e permite analisar a influência de diferentes forças sociais no âmbito jurídico. É fácil de visualizar o pluralismo jurídico quando se fala, por exemplo, na lex mercatória ${ }^{80} \mathrm{o}$ desafio para o estudo do direito consiste em perceber que existe também um pluralismo na área ambiental, que é estatal por excelência.

Com uma aceitação cada vez maior da teoria pluralista, essa não é mais uma questão de sociologia legal, mas se torna um desafio na prática dela mesma. ${ }^{81}$ Para a sua compreensão, importa observar algumas ideias-chaves, como a análise sistêmica, assim como chamar atenção para os limites do pluralismo na análise do direito.

A Teoria dos sistemas sociais ${ }^{82}$ tem sua importância epistemológica por ser capaz de identificar as influências sociais como sistema e buscar analisar a interação entre elas. Estuda os diferentes setores sociais como sistemas autônomos entre si, negando teorias sociais que consideram os campos sociais relativamente autônomos ou

${ }^{80}$ Sobre a lex mercatoria, veja o capítulo de Marlon Tomazette.

${ }^{81}$ TEUBNER, Gunter. Breaking frames: Economic globalisation and the emergence of Lexmercatoria. European Journal of Social Theory, v. 5, p. 199-217, 2002.

${ }^{82}$ Segundo Luhmann, a teoria dos sistemas se refere ao mundo real, com a preocupação de provar-se diante da realidade. Luhmann explica englobar, com a teoria dos sistemas sociais, todo o objeto da sociologia, o conjunto de todos os contatos sociais possíveis. LUHMANN, Niklas. Sistemas sociales: Lineamientos para uma teoria general. Trad. Silvia Pappe y BrunhildeErker; coord por Javier Torres Nafarrete - Rubi (Barcelona): Anthropos; México: UniversidadIberoamericana; Santafé de Bogotá: CEJA, Pontifícia UniversidadJaveriana, 1998. p. 37-39. 
completamente mesclados uns aos outros. ${ }^{83}$ Aqui entram os entendimentos sobre a autonomia, interdependência, corrupção e racionalidade universal.

Sobre a autonomia, essa é a linguagem própria de cada campo. ${ }^{84}$ É possível observar, por exemplo, porque se sugere a relação do campo jurídico com os demais campos em sociedade, o jurídico sendo mantido diante do domínio de quem tem o conhecimento jurídico, e de quem não tem. ${ }^{85} \mathrm{~A}$ diferença de um sistema com o seu entorno identifica seu limite, diante do qual os sistemas interagem e se regulam. ${ }^{86}$ A questão é que, diante dos processos de globalização, o conhecimento jurídico estende o seu campo de especialização e criação de normas diante das impressões externas setoriais globalizadas.

A teoria dos sistemas afirma, então, uma autonomia não relativizada, de forma que, quando os sistemas interagem, não é a mera troca de informação, mas a criação de informação em cada sistema diante das impressões externas (de outros sistemas). ${ }^{87}$ Essa troca justifica o funcionamento e legitimidade de seu próprio sistema, buscando cognições, conceitos e entendimentos de outros sistemas. ${ }^{88} \mathrm{O}$ ponto de encontro dessa interação são os acoplamentos estruturais. ${ }^{89}$ Consistem em institutos de um sistema tomando o conceito ou/e significado de um instituto ou linguagem de outro sistema para dar-lhe função e sentido.

${ }^{83}$ FEBRAJO, Alberto; TEUBNER, Gunter. Autonomy and regulation in the autopoietic perspective: an introduction. In: FEBRAJO, Alberto; TEUBNER, Gunter. State, Law and economy as autopoietic systems: regulation and autonomy in a new perspective. Milan, Dott. A. GiuffrèEditore, 1992. p. 5-16.

${ }^{84}$ WITTGENSTEIN, Ludwig. Philosophical Investigations. Translated by G. E. M. Anscombe.3. ed. Blackwell Oxford UK \& Cambridge USA, 1967. p. 12.

${ }^{85}$ BOURDIEU, Pierre. A força do direito: elementos para uma sociologia do campo jurídico.

${ }^{86}$ LUHMANN, Niklas. Sistemas sociales: Lineamientos para uma teoria general. Trad. Silvia Pappe y BrunhildeErker; coord por Javier Torres Nafarrete - Rubi (Barcelona): Anthropos; México: UniversidadIberoamericana; Santafé de Bogotá: CEJA, Pontifícia UniversidadJaveriana, 1998. p. 40.

${ }^{87}$ FEBRAJO, Alberto; TEUBNER, Gunter. Autonomy and regulation in the autopoietic perspective: an introduction. In: FEBRAJO, Alberto; TEUBNER, Gunter. State, Law and economy as autopoietic systems: regulation and autonomy in a new perspective. Milan, Dott. A. GiuffrèEditore, 1992. p.5-16.

${ }^{88}$ NEVES, Marcelo. Transconstitucionalismo. São Paulo: M. Fontes, 2009. p.120.

${ }^{89}$ NEVES, Marcelo. Transconstitucionalismo. São Paulo: M. Fontes, 2009. p.120.
Nesse sentido, os sistemas são autônomos por sua estrutura e modo de operar específicos, que os diferem uns dos outros, mas buscam sua funcionalidade e legitimidade fora de sua autonomia, seja nos setores sociais que regulam, seja com os sistemas sociais que interage.

Entretanto, por mais que essa teoria pretenda uma autonomia aos sistemas sociais, é possível observar que os processos de globalização setoriais são de tal força que um setor pode acabar por dominar outro, tal como mencionado na relação entre globalização e direito.

O domínio da lógica de um sistema sobre outro é o que Marcelo Neves analisa como a corrupção do sistema, identificado pela prevalência de conceitos de outros sistemas e diminuição dos seus conceitos próprios. Quando um conceito cognitivo de um sistema predomina sobre o outro, a ponto de não ter capacidade de superar, ocorre a corrupção do sistema. Nesse sentido, o processo de racionalização das ordens desses sistemas não é fechado, mas transversal, ou seja, uma mútua legitimação.

Essa forma de analisar os fatos sociais, por sua perspectiva sistêmica e não necessariamente hierárquica, se torna ideal para o entendimento dos efeitos da globalização na sociedade, em especial, no direito. Possibilita, pois, a análise em um contexto de normas em rede, em sistemas de governança e regimes jurídicos, com ou sem a participação do Estado, levando-se em conta a influência dos diferentes setores envolvidos no direito.

É nesse contexto que o pluralismo jurídico, que engloba uma abordagem sistêmica de analisar os fatos, vem sendo cada vez melhor recepcionado no estudo do direito, vislumbrando a coexistência de ordens e diferentes elementos a impulsionar a criação e efetividade do direito. O pluralismo jurídico destaca-se por analisar o conflito de forma sistêmica, ou seja, na compreensão das lógicas normativas envolvidas, que podem se diferir e entrarem em conflito.

No que diz respeito às características, no pluralismo jurídico, o direito será direito porque as partes assim o consideraram e o âmbito jurídico assim o trata. ${ }^{90}$ Sua noção permanece na velha associação do direito à busca pela ordem. Se junta o conceito de direito à noção mais

\footnotetext{
${ }^{90}$ TEUBNER, Gunter. Global Bukowina: Legal Pluralism in the World Society. In: GUNTHER Teubner (Ed.). Global Law Without a State. Dartmouth, Aldershot 1997. p. 3-28.
} 
primitiva do direito, como pacto entre as partes, por instrumentos normativos. A dificuldade está, então, em achar seus limites, eis a importância epistemológica de se definir exatamente o que está estudando, será essa, pois, a ação que delineará os limites da análise, e não o conceito de direito em si. De modo complementar a esse conceito simples de direito, tem-se que as normas nascem da interação entre as ordens sociais e da repercussão dos regimes jurídicos formados.

Sobre as fronteiras pluralistas, é preciso visualizar não mais pelo conflito territorial, como era na teoria estatal, mas pelo conflito sistêmico entre as lógicas de cada sistema. Isso envolve a necessidade de se compreender a lógica que prevalece em cada um desses sistemas, ou seja, o modo como funcionam, como trabalham e defendem seus bens e valores jurídicos. ${ }^{91}$

Por exemplo, ao se estudar o direito econômico e sua relação com a proteção ambiental, precisamos entender que existem diferentes lógicas envolvidas, a lógica ambiental, de um lado, e a econômica, de outro. Compreendendo como funcionam, é possível ver como podem, inclusive, entrar em conflito. São as diferenças de suas racionalidades, em seu modo de entender os interesses que pretendem defender, e ainda no modo como defendem tais interesses.

Nesse sentido, o conflito intersistêmico é, por definição, muito mais que apenas um mero conflito entre normas, envolve, então, um conflito entre racionalidades, entre a lógica de cada regime, entre seus princípios, entre seus objetivos. ${ }^{92}$ Entra em destaque, então, que a norma de cada setor tem forte relação de dependência com as fontes de força e características do sistema social ao qual pertence. ${ }^{93}$

É essa relação de dependência a própria caracterização de funcionalidade da norma, dando-lhe legitimidade. Atentar-se para os conflitos que vão além da norma

${ }^{91}$ FISCHER-LESCANO, Andreas; TEUBNER, Gunter. Regimes-Collisions: the vain search for legal unity in the fragmentation in global law. Translatet by Michelle Everson. Michigan Journal of International Law, v. 25, n. 999, p. 199-1046.

92 BURGENMEIER, Beat. Economia do desenvolvimento sustentável. Tradução Ana André. Lisboa: Instituto Piaget, 2009. p. 12.

${ }^{93}$ Delmas-Marty identifica a interdependência como parte da racionalização jurídica, para dar margem à transparência, valorizando a argumentação jurídica. DELMAS-MARTY, Mireille. Les forces imaginantes $d u$ droit. Le relatif et l'universel. Éditions du seuil, p. 16. é atentar-se para os conflitos entre os contextos de seus sistemas sociais respectivos, aos quais a norma pertence $\mathrm{e}$ não pode ser vista plenamente como um elemento totalmente independente. Os sistemas são interdependentes na busca de funcionalidade e legitimidade, mas, quando operam, cada um dos campos possui sua própria linguagem, que lhe dá autonomia.

Das outras características do pluralismo, merece destaque o entendimento de Teubner, na ideia de centro e de periferia, para o entendimento das fontes no direito pluralista: a descentralização ${ }^{94}$ da força criadora do direito para não mais somente o Estado e outros focos, segundo ele, periféricos, de poder. ${ }^{95}$

Com o auxílio do pluralismo jurídico, é possível afirmar que o direito emerge de vários processos imersos na globalização em múltiplos setores da sociedade civil e envolve sua tecnicidade e especialização, independentemente do direito estatal. O direito global emerge mais das periferias sociais que dos centros políticos estatais. Nesse sentido, as fontes do direito global se estendem para serem encontradas também em processos auto-organizados de acoplamento do direito em processos de globalização, com alta natureza especializada e técnica. ${ }^{96}$

Eis o caso do ICSID. O pluralismo jurídico aqui tem dimensões mais amplas que a simples afirmação da presença de diferentes ordens jurídicas, referindo-se às consequências de relativização do Estado frente à influência de atores não estatais. A ordem jurídica ambiental tem por desafio adequar-se à ordem jurídica do regime de proteção de investimentos estrangeiros. Contudo, para a teoria do direito, não é possível pretender um conceito de direito como sendo, sobretudo, estatal, mas admitir que diferentes ordens jurídicas coexistem e surgem, inclusive, da tensão entre os regimes jurídicos distintos.

\footnotetext{
${ }^{94}$ A descentralização das fontes é reflexo da crescente exigência por maior tecnicidade dos setores sociais, e, de um ponto de vista jurídico, se origina na atribuição de competências e capacidades estatais às organizações, permitindo a produção e controle do direito para além do Estado. VARELLA, Marcelo Dias. A crescente complexidade do sistema jurídico internacional. Alguns problemas de coerência sistêmica. Revista de Informação Legislativa. Brasília a. 43 n. 167 jul./ set. 2005.

95 TEUBNER, Gunter. Breaking frames: Economic globalisation and the emergence of Lexmercatoria. European Journal of Social Theory, v. 5, p. 199-217, 2002.

${ }^{96}$ TEUBNER, Gunter. Global Bukowina: Legal Pluralism in the World Society. In: GUNTHER Teubner (Ed.). Global Law Without a State. Dartmouth, Aldershot 1997. p. 3-28.
} 
Ver emergir outras ordens além da ordem estatal não significa que essa tenha descaracterizada a sua importância. O Estado permanece na defesa do interesse social e a ordem pública abrange ou, pelo menos, deve abranger o fornecimento da seguridade pública, bom funcionamento dos serviços públicos, direitos e seguridade dos cidadãos, enfim, diferentes mecanismos de garantia de ordem na sociedade. ${ }^{97}$

No contexto pluralista, tem-se então que cada ordem é fiel aos princípios e objetivos e à lógica dos seus sistemas sociais, que lhe dão funcionalidade e legitimidade. Por exemplo, a ordem econômica reflete o interesse econômico dos atores envolvidos, a ordem estatal, o interesse geral, a justiça, a organização da sociedade. Nesse entendimento, o Estado não perde sua vez, sendo responsável por interesses de suas sociedades, se contrários aos interesses de outras forças sociais. $\mathrm{O}$ direito emerge para dirigir conflitos e exerce seu velho papel de instrumento de mediador de diferentes interesses.

Assim, uma vez superada essa perspectiva teórica de se migrar de uma análise meramente estatal do direito para uma inserida nessa abordagem pluralista e sistêmica, é possível agora passar para o segundo aspecto que os casos Metalclad, Tecmed e Santa Elena permitiram identificar: estudar a interação entre ordens jurídicas distintas, na presença de atores também não estatais, a fim de averiguar a efetividade de seus sistemas jurídicos, análise que se segue.

\subsection{A relativização da ação de regulamentação ambiental do Estado face à proteção dos investimentos estrangeiros}

Os casos Metalclad, Tecmed e Santa Elena ilustraram a interação entre ordens jurídicas distintas e, nessa relação, a relativização da ação de regulamentação ambiental do Estado face à proteção dos investimentos estrangeiros. Consiste em situação trazida pelo enredo dos efeitos da globalização no direito e que permite, aqui, o estudo da efetividade jurídica dos campos normativos envolvidos. Sendo meio ambiente e investimentos estrangeiros matérias com campos jurídicos distintamente especializados, busca-se compreender alguns elementos do choque das respectivas lógicas (econômica e ambiental),

\footnotetext{
${ }^{97}$ Sobre a importância do Estado em um campo transnacional, veja o capítulo de Karla Margarida.
}

para, em segundo lugar, identificar quais as consequências de tal relação, pela análise direta dos casos.

\subsubsection{Alguns elementos da relação entre proteção ju- rídica ambiental e proteção jurídica dos investi- mentos estrangeiros}

Como já mencionado, casos como o do Metalclad, Tecmed e Santa Elena trazem à tona, no mínimo, a necessidade de melhor esclarecimento sobre a relação entre a proteção do meio ambiente e a proteção de investimentos estrangeiros, que é ainda bastante complexa. Como primeiro motivo, basta analisar o funcionamento do ICSID. É um grande desafio procurar ver realizada a proteção do meio ambiente em uma instituição parte de um regime predominantemente econômico, no qual o campo privado e sua lógica individualista possuem peso dominante.

O ICSID é uma instituição internacional autônoma, ${ }^{98}$ estabelecida pela Convenção de Washington, ${ }^{99}$ com mais de 140 Estados membros. Entrou em vigor em 1966, fazendo parte do campo jurídico de proteção de investimentos, regida por uma lógica predominantemente econômica. A proteção ambiental, por outro lado, é matéria tipicamente estatal, cujos arranjos jurídicos, a priori, encontram-se vinculados à ação do estado, seja no campo das normas nacionais, seja no direito internacional.

O direito internacional dos investimentos emerge de um prolongamento do direito da condição dos estrangeiros, com fundamento de ordem ética voltado para a proteção da pessoa, para que ela possa exercer atividades econômicas. Com o desenrolar das relações econômicas, torna-se cada vez mais sensível a uma ordem nesse senti-

\footnotetext{
${ }^{98}$ Artigo 18 da Convention on the Settlement of Investment Disputes between States and Nationals of other States. Disponível em: <http://icsid.worldbank.org/ICSID/StaticFiles/basicdoc_ spa-archive/16.htm> Acesso em: 15 nov. 2011.

${ }^{99}$ Convenção de Washington ou a Convenção sobre Resolução de Conflitos relativos a Investimentos entre Estados e Nacionais de outros Estados. Em inglês: Convention on the Settlement of Investment Disputes between States and Nationals of other States. Disponível em: <http://icsid.worldbank.org/ICSID/StaticFiles/basicdoc_en-archive/9.htm> Acesso em: 15 nov. 2011. A Convenção, tratado multilateral, estabelece o mandato do ICSID, sua organização e funções. Foi aberta para assinatura, no campo de atuação do Banco Internacional para a Reconstrução e desenvolvimento (Banco Mundial), em 18 de março de 1965 e entrou em vigor em 14 de outubro de 1966. ICSID. About ICSID. Disponível em: <http://icsid.worldbank. org/ICSID/ICSID/AboutICSID_Home.jsp>. Acesso em: 15 nov 2011.
} 
do, voltando-se mais para a proteção da mobilidade dos fatores de produção. ${ }^{100}$

O ICSID apresenta papel importante nos investimentos internacionais e no desenvolvimento econômico, atuando como um fórum internacional, com o propósito de prover uma estrutura para conciliações e arbitragens em disputas de investimentos. As comissões de conciliação e tribunais arbitrais são constituídas caso a caso. ${ }^{101}$ Outro detalhe jurídico relevante em seu funcionamento é que o recurso à instituição é sempre pelo consentimento das partes. ${ }^{102}$ Além disso, ao estabelecer a capacidade de um indivíduo ou uma empresa integrar uma relação jurídica junto com um ator estatal, vale mencionar que o funcionamento do ICSID contribui para a tese do reconhecimento do indivíduo como sujeito de direito internacional. ${ }^{103}$

Além disso, o desenvolvimento dos investimentos internacionais e as operações financeiras são facilitados por um movimento geral de desregulamentação, reforçando a autonomia das empresas. ${ }^{104} \mathrm{O}$ resultado é um regime jurídico extremamente protetor do investidor estrangeiro, em uma ordem cuja predominância na lógica econômica acaba tornando pequeno o espaço para o poder de regulamentação do Estado. O problema é que a proteção ambiental é tradicionalmente vinculada à regulamentação estatal, e não à sua desregulamentação.

Então, em se tratando de violações a investimentos estrangeiros, o Estado pode ver suas ações sendo questionadas, tornando difícil a implementação de políticas públicas ambientais, quando permeia o campo dos in-

${ }^{100}$ CARREAU, Dominique; JUILLARD, Patrick. Droit International économique. 3. ed. Paris: ÉditionsDalloz, 2007. p. 398.

${ }^{101}$ Para mais informações sobre o funcionamento do ICSID em: ICSID. About ICSID. Disponível em: <http://icsid.worldbank.org/ICSID/ICSID/AboutICSID_Home.jsp .>. Acesso em: 15 nov 2011.

${ }^{102}$ Convention on the Settlement of Investment Disputes between States and Nationals of other States. Disponível em $:<\mathrm{http}: / /$ icsid.worldbank.org/ICSID/StaticFiles/basicdoc_spa-archive/11.htm>. Acesso em: 15 nov. 2011.

${ }^{103}$ PEREIRA, Celso de Tarso. O Centro Internacional para a Resolução de Conflitos sobre Investimentos (CIRCI - ICSID). Revista de Informação Legislativa, Brasília ano 35 n. 140, p. 87-93, out./dez. 1998.

${ }^{104}$ LAFAY, Gérard. Nations et entreprises dans l'économie mondiale. In : HUMBERT, Marc. Colloque du Greco CNRS-EFIQ. Investissement international et dynamique de l'économie mondiale. Paris: Economica, 1990. p. 61-69, p. 69. MARAIS, Bertrand du. Droit Public de La régulation économique. Presses de Sicences PO etDalloz, 2004. p. 2. vestimentos. Nesse sentido, a proteção ambiental se torna um desafio, na medida em que o ICSID é uma instituição em que o poder de regulamentação do Estado é muito limitado. O desafio se constrói então na interação entre as lógicas ambiental e econômica e na relação entre as ordens normativasA lógica ambiental, em contraste com a lógica econômica, é um desafio para a proteção do meio ambiente na sua relação com a proteção dos investimentos, pela sua própria sistemática.

A evolução da proteção jurídica ambiental ${ }^{105}$ e a ordem pública ecológica ${ }^{106}$ são o conjunto de atos constitucionais ou legislativos que protegem o meio ambiente, revelando o interesse geral. Vislumbra-se uma explosão de leis ambientais pelos países, assim como uma série de tratados, declarações e outras normas internacionais, ao mesmo tempo em que as multinacionais se multiplicam e se espalham, instalando-se pelos países.

O resultado é o tratamento do meio ambiente como material entre Estados, que faz negligenciar outra dimensão, quando o meio ambiente entra na esfera privada ou outras esferas não estatais. ${ }^{107} \mathrm{Tem}$-se, clara, a influência da proteção ambiental em outros campos, exigindo, por exemplo, do direito econômico, algum tipo de exceção ambiental, como existe na OMC, que é por definição exceção e ainda permanece estatal.

Pode-se, então, afirmar a complexidade da relação, na medida em que casos como o da Metalclad, Tecmed e Santa Elena estão no âmbito das consequências da prática de dumping ambiental, que ocorre quando atores privados e outros atores não estatais utilizam meios jurídicos, fiscais e econômicos para aumentarem seus lucros, deslocando unidades produtivas para países com legislação

\footnotetext{
${ }^{105}$ Para uma evolução histórica da proteção jurídica ambiental: KISS, A. Introduction to International Environmental Law. $2^{\text {nd }}$ Revised Edition, , Geneva, Switzerland: UNITAR, 2005. p. 28-29. ${ }^{106}$ KISS, Alexandre. L'ordre public écologique. In FRITZ, JeanClaude (Dir.) L'ordrepubliccécologique. Towards an ecological public order. Bruyant, Bruxelles: 2005 p. 157.

${ }^{107}$ SAND, Peter H. Transnational Environmental Law. Lessons in Global Change. (International Environmental Law and Policy Series, v. 53). Klumer Law International.The HagueLondon-Boston, 1999, p. 35.
} 
ambiental mais flexível e fraca capacidade institucional. ${ }^{108}$ É preciso, pois, considerar o peso da lógica econômica pairando no âmbito dos investimentos, obtendo como variável importante o peso e efeito de dominação entre as economias de cada país. ${ }^{109}$

Nesse sentido, era só uma questão de tempo até começarem a surgir interferências sistêmicas entre os campos jurídicos. Se olharmos para os setores sociais de cada âmbito e verificarmos as diferenças básicas em suas racionalidades, ${ }^{110}$ não é difícil perceber como é fácil colidirem.

De modo geral, enquanto a proteção ambiental segue uma perspectiva holística, levantada em nome do bem e de toda a coletividade, voltada para a cooperação entre os atores, os investimentos estrangeiros, por outro lado, são protegidos por um raciocínio econômico e individualista, com a prevalência de um caráter competitivo, mais que de cooperação, voltado para o lucro, em que o

${ }^{108}$ Dumping ambiental aqui entendido como as práticas de transferência de indústrias poluentes para os países em desenvolvimento, em geral com fracas legislações ambientais, não é sinônimo de dumping, relacionado ao comércio, somente. TOMAZETTE, Marlon. O Conceito do dumping para a regulamentação multilateral do comércio internacional. Prismas: Dir., Pol. Pub. e Mundial, Brasília, v. 4, n, 1, p 194-214, jan/ jul. 2007. Disponível em: <http://www.publicacoesacademicas.uniceub.br/index.php/prisma/article/viewFile/222/223>. Acesso em 26 jul. 2011.

${ }^{109}$ HUMBERT, Marc. Le concept de système industriel mondial. In: HUMBERT, Marc. Colloque du Greco CNRS-EFIQ. Investissement international et dynamique de l'économie mondiale. Paris: Economica, 1990. p. 36-60, p. 45ç.

${ }^{110}$ Fischer-Lescano e GunterTeubner demonstram as diferentes ordens na perspectiva do direito fragmentado, ao exemplo da lex mercatória com sua racionalidade econômica colidindo com a lógica da WHO e as normas vindas do sistema de saúde; a lexconstructionis, demonstrando o código de construções colidindo com o direito internacional ambiental. FISCHERLESCANO, Andreas; TEUBNER, Gunter. Regimes-Collisions: the vain search for legal unity in the fragmentation in global law. Translatet by Michelle Everson. Michigan Journal of International Law, v. 25, n. 999, p. 199-1046, . p. 199-1046. No âmbito do OSC na OMC, por exemplo, a relação entre comércio e meio ambiente tem suas dificuldades (do ponto de vista ambiental) até nas normas procedimentais. $\mathrm{O}$ acesso é restrito a Estados; o ESC apenas concede terceiros, com interesse substancial no conflito, ou seja, também Estados; nesse sentido, grupos ambientais não governamentais e outros interessados apenas podem apresentar seus argumentos por meio de lobbies junto aos governos de seus países. WEISS, Edith Brown; JACKSON, John J. O enquadramento dos conflitos entre meio ambiente e comércio. In: VARELLA, Marcelo Dias; BARROS-PLATIAU, Ana Flávia (Org.). Proteção internacional do meio ambiente. Brasília: UNITAR, UniCEUB, UnB, 2009. p.295-344; p. 324. fator meio ambiente não é melhor que a proteção da liberdade para os investimentos.

São características que refletem no direito e na sua aplicação. ${ }^{111}$ As diferenças entre as lógicas estão nas diferenças entre os objetivos almejados por cada âmbito e a direção e os instrumentos dados por esses objetivos. ${ }^{112}$ Enquanto a proteção dos investimentos estrangeiros, pela lógica econômica, tem por traços, em seus objetivos, o liberalismo e intervenção mínima do Estado na atuação no mercado, a proteção ambiental sugere ser feita pela intervenção do Estado na economia.

Enquanto os investimentos estrangeiros possuem a arbitragem internacional como técnica de efetividade por excelência, as técnicas e procedimentos para a proteção ambiental podem variar de medidas regulatórias, estabelecimento de princípios e orientações, restrições, estudos de impactos ambientais, licenciamentos, auditorias e relatórios, com a presença da atuação estatal em todo momento. ${ }^{113}$ Tais técnicas ambientais podem representar, em diferentes formas, a intervenção do Estado na economia, de forma que não é difícil compreender como tais ações podem, por vezes, interferir nos investimentos estrangeiros e caracterizar uma violação a eles.

É o que ocorreu nos casos Metalclad, Tecmed e Santa Elena, nos quais medidas ligadas a normas ambientais foram questionadas, em uma instituição com a predominância da lógica econômica, por terem afrontado normas de proteção de investimento, também com o domínio da lógica econômica.

Mais uma vez, é fácil definir como desafio a proteção ambiental no ICSID, pois além de a regulamentação estatal ser facilmente mitigada dado o seu funcionamento, as normas ambientais e de proteção de investimento

\footnotetext{
${ }^{111}$ Philippe Le Preste contrasta tais diferenças entre o ambiental e o econômico no direito internacional, comparando a lógica das normas da OMC com a lógica das normas ambientais, demonstrando as fortes e graves deficiências destas. LE PRESTRE, Philippe; MARTIMORTO-ASSO, Benoît. A reforma na governança internacional do meio ambiente: os elementos do debate. In: VARELLA, Marcelo Dias; BARROS-PLATIAU, Ana Flávia (Org.). Proteção internacional do meio ambiente. Brasília: UNITAR, UniCEUB, UnB, 2009. p. 407.

${ }^{112}$ BURGENMEIER, Beat. Economia do desenvolvimento sustentável. Tradução Ana André. Lisboa: Instituto Piaget, 2009. p. 12.

${ }^{113}$ SHELTON, Dinah. Techniques and procedure in international environmental Law. $2^{\text {nd }}$ Edition, , Geneva, Switzerland: UNITAR, 2004. p.04-05.
} 
seguem lógicas distintas. Sem pretender afirmar que estarão sempre em colisão, é preciso apenas ressaltar que são objetos distintos que seguem lógicas jurídicas distintas e que, por isso, em uma relação entre eles, a tendência é que uma das duas lógicas prevaleça, os casos demonstram a prevalência da lógica econômica.

Ademais, não é somente o funcionamento do ICSID, junto com a explosão de normas ambientais e a multiplicação de multinacionais, a causa que fomentou relação entre os investimentos e o meio ambiente. Nos casos estudados, verifica-se, como um dos elementos causais para a questão "meio ambiente" ter sido levada ao ICSID, a insuficiência do ramo jurídico ambiental (o direito público e ação estatal) para o tratamento da questão. Parecendo estar diretamente relacionada à questão do dumping ambiental, tal insuficiência se deu pela fraca capacidade institucional dos Estados demandados, que não conseguiram resolver a questão da expropriação apenas com sua legislação nacional.

Nesse sentido, é possível observar algumas problemáticas como consequências da relação entre a proteção ambiental e a proteção dos investimentos estrangeiros: o funcionamento da instituição é de tal forma que a regulamentação ambiental é fragilizada em nome da proteção dos investimentos; em caso de conflitos das lógicas de cada proteção, a tendência é prevalecer a lógica econômica, pois rege a proteção dos investimentos e também a própria instituição; e, por fim, as medidas questionadas no ICSID parecem estar diretamente ligadas à fraca capacidade institucional dos Estados em tratar dessa relação entre a proteção ambiental e a proteção dos investimentos, melhor desenvolvidos a seguir.

\subsubsection{Algumas reflexões sobre as consequências da relação entre a proteção ambiental e a prote- ção de investimentos estrangeiros.}

$\mathrm{Na}$ complexa relação entre proteção ambiental e investimentos, não apenas o conflito de racionalidades e a fraqueza institucional ambiental se destacam, mas também o papel dos investimentos na mudança da percepção das políticas governamentais, assim como o papel da própria arbitragem. Além disso, do ponto de vista da eficácia e técnica jurídica, os casos demonstram a importância de se compreender o instituto da expropriação para a proteção ambiental.

Ao que diz respeito ao papel dos investimentos na mudança da percepção do Estado e de suas políticas go- vernamentais, os governos têm que considerar suas políticas, com encorajamento e competição saudável, e evitar políticas que atacam o capital, em termos de saúde e normas ambientais. ${ }^{114} \mathrm{O}$ raciocínio segue o fato de que a ação de regulamentação do Estado já é relativizada face à proteção dos investimentos, de modo que precisamos, então, perceber como tal relativização influencia a ação estatal.

Para além disso, os investimentos são o provimento de capital e transferência de tecnologia, podendo, assim, cumprir promessas de desenvolvimento sustentável, se bem direcionados. É preciso, de um lado, o fortalecimento de fraquezas institucionais, para que o governo consiga dialogar interesse geral com proteção dos investimentos e, de outro lado, maior flexibilização no setor da proteção dos investimentos.

Outra característica que chama atenção é a própria utilização da arbitragem em meio ambiente. Em seu caráter pragmático, logo pontua especificamente quais os problemas presentes, já coloca as cartas na mesa de imediato. ${ }^{115}$ Nesse sentido, a arbitragem pode ser apresentada como uma solução apta à velocidade na resolução de conflitos exigida pela globalização. As vantagens, em geral, podem ser vistas pela possibilidade de eleger um árbitro por sua perícia e estar esta relacionada a uma questão de desenvolvimento e proteção ambiental, assim como poder escolher as normas que regerão o conflito. ${ }^{116}$

Entretanto, se vamos aos casos práticos, vemos a complexidade da prevalência da lógica econômica sobre a proteção ambiental. Diante disso, podemos então chamar atenção para a necessidade de maior flexibilização do mecanismo do ICSID e sua abertura para questões ambientais.

Nessa flexibilização, por um ponto de vista técnico, podemos analisar melhor a expropriação. Nos casos

${ }^{114} \mathrm{JHA}$, Veena. Part. The role of foreing direct investment.The case of India. In: WARD, Halina; BRACK, Duncan (Ed.). Trade, Investment and the Environment. Proceedings of the Royal Institute of International Affairs conference, Chatham House, London, October 1998. The Royal Institute of international Affairs, Energy and Environmental Programme. London: EarthscanPublicationsLtd, 2000. p. 211.

${ }^{115}$ ROMANO, Cesare P. R. The Peaceful Settlement of International Environmental Disputes.A pragmatic approach. (International Environmental Law and Policy Series, v.56).Klumer Law International. The Hague-London-Boston, 2000, p. 323.

${ }^{116}$ CLAY, Thomas; ABOIM, Luiz Claudio. Arbitragem e meio ambiente. Revista brasileira de arbitragem, v. 4, p. 32-43, 2004. p. 32-43. 
analisados, as medidas que foram levadas à arbitragem do ICSID foram reconhecidas como violação porque tiveram o efeito de expropriação. É possível observar que o investidor estrangeiro é protegido não somente por expropriações reais, mas por medidas que tenham o mesmo efeito, ou seja, privam uma pessoa de sua propriedade. É relevante atentar-se para o fato de que o motivo da expropriação não importa muito para caracterizar a violação.

Além disso, se a expropriação, ainda que por motivo legal e legítimo, tenha sido "aceita" pelo ICSID, a ausência de indenização é adicionada à caracterização do dano. Então o Estado se vê na seguinte situação: ou a expropriação ambiental já parece caracterizar violação aos investimentos estrangeiros, ou o Estado fica condicionado sempre a pagar para utilizar o seu exercício regular de direito, na presença de um investimento estrangeiro. A pagar ou pela indenização ou por ter que ir mesmo ao ICSID resolver a demanda.

Percebendo essa problemática, Sabrina Robert fez uma análise do caso Metalclad e outros casos, procurando estudar como proteger o poder de regulamentação do Estado nessa situação e como gerenciar o ônus do custo da satisfação do interesse geral. Observou que resta como grande problema a proteção quase absoluta dos investimentos estrangeiros, que tem como critério fundamental o efeito da medida, para análise da violação. ${ }^{117}$

A expropriação, na forma como é interpretada, assim também como do Mercosul etc. A ausência de uma forma de análise melhor sistematizada, acerca das razões da medida, prejudica o interesse geral, tornando demasiadamente desproporcional a análise da violação, ou não, a investimentos estrangeiros. Nesse sentido, determina como essencial a abertura da análise da expropriação para os princípios de proteção ambiental, uma vez que, face à imprecisão dos critérios de análise, a apreciação dos árbitros é determinante. ${ }^{118}$

Sabrina Robert propõe, então, por um ponto de vista de eficácia jurídica, ou seja, do uso e interpretação da norma, que a análise da proporcionalidade pode ser em vista dos efeitos da medida também para o Estado. Nessa análise da proporcionalidade, considera importante a diferença entre expropriação e desapropriação direta, por um critério de análise de lucro com a medida estatal tomada. A autora observa, nesse sentido, que, na expropriação, a apropriação pelo Estado pretende dedicar o lucro para o bem estar da comunidade, e, na desapropriação direta, são medidas que restrinjam efetivamente atividades nocivas ao interesse comum. ${ }^{119}$

Nesse sentido, uma análise dos efeitos da medida parece necessária na análise da existência ou não de dano, de expropriação. Deve ser introduzida no campo da proteção dos investimentos, como forma de ponderação desses interesses com o interesse geral de proteção ambiental. É um raciocínio que segue com a necessidade cada vez maior de descentralizar também do Estado, o ônus com a proteção ambiental.

Em outras palavras, a responsabilidade ambiental precisa ser mais um estabelecimento de normas e procedimentos em campos não estatais, face aos riscos ambientais, ao invés de sua noção tradicional de função se-

${ }^{118}$ ROBERT, Sabrina. La Protection du Pouvoir de Réglementation Environnementale de l'Etat dans le Cadre du Contentieux de l'Expropriation Indirecte. Investissement International et Protection de l'Environnement. Disponível em $:<w w w . e s i l-$ -sedi.eu/english/Paris_Agora_Papers/Robert.PDF $>$. Acesso em: 22 nov. 2011.

${ }^{119}$ ROBERT, Sabrina. La Protection du Pouvoir de Réglementation Environnementale de l'Etat dans le Cadre du Contentieux de l'Expropriation Indirecte. Investissement International et Protection de l'Environnement. Disponível em $:<w w w . e s i l-$ -sedi.eu/english/Paris_Agora_Papers/Robert.PDF $>$. Acesso em: 22 nov. 2011. 
parada dos agentes públicos. ${ }^{120} \mathrm{Na}$ relação intersistêmica, significa a influência da lógica da proteção ambiental no campo econômico e na gestão das empresas. ${ }^{121}$ Nesse sentido, paira sobre a proteção dos investimentos, também, a responsabilidade ambiental.

Entretanto, tal perspectiva, além de ser o raciocínio básico do discurso da proteção do meio ambiente, é ainda parte de uma relação nova, que é a exigência de padrões ambientais também no âmbito privado. E, como tal, ainda tem muito a andar. Por exemplo, um efeito inverso vem ocorrendo nos acordos de investimento: ao invés de inserir a alocação dos riscos ambientais, via tratado, estão excluindo-a expressamente de seu campo de responsabilidade.

Tal afirmação pode ser ilustrada pelo Tratado para a Carta sobre Energia (Energy ChapterTreaty), ${ }^{122}$ que contempla metas e normas de cooperação entre as partes para a promoção de empreendimentos voltados para a produção de energia, cujas demandas podem ser resolvidas pela Corte Permanente de Arbitragem. O Tratado prevê meios coercivos para resolução de controvérsias sobre os investimentos, inclusive a Corte Permanente de Arbitragem, mas, para questões ambientais, apenas soft norms.

Contudo, para todos os efeitos, no momento em que normas ambientais interferem em investimentos, elas farão parte da análise do árbitro, por isso sua interpretação é importante. Diante do Tratado para a Carta sobre Energia, foi vislumbrado interessante caso entre a Plama Consortium Limited (de Cyprus) e a República da Bulgária na Corte Permanente de Arbitragem. O que envolveu o meio ambiente na decisão arbitral foi a necessidade de apreciação da legislação ambiental surgida em 1999, responsabilizando a Plama a arcar com danos ambientais anteriores à aquisição do empreendimento e com a produção de energia, isso constituía violação ao artigo 10 do

${ }^{120}$ GRANT, Malcolm. Introduction. Enforcement: Who enforces? How? Whether Effective? In CHAIRMAN, Patricia Thomas. Environmental liability: IAB Section on Business Law $7^{\text {th }}$ residential seminar on environmental law, 9-13, 1990. Switzerland, p. 213-218.

${ }^{121}$ BURGENMEIER, Beat. Beat. Les nouvelles formes $\mathrm{d}$ 'investissement international et les strategies des firmes. In HUMBERT, Marc. Colloque du Greco CNRS-EFIQ. Investissement international et dynamique de l'économie mondiale. Paris: Economica, 1990. p. 213-221.

${ }^{122}$ Tratado para a Carta sobre Energia (Energy ChapterTreaty). Disponível em: <http://www.encharter.org/index. php?id=269> Acesso em 02. nov. 2011.
ECT. A reclamação afirmou que a legislação tinha o intuito de prejudicar os investidores da Plama. Entretanto, pela decisão arbitral, não houve evidências de que a legislação ambiental surgiu para prejudicar os investidores, mas foi uma apreciação de problemas ambientais locais, não caracterizando a proteção ambiental como violadora dos interesses da empresa. ${ }^{123}$

Nesse raciocínio, está na flexibilização das regras de proteção dos investimentos assim como na interpretação dos árbitros a chave para uma relação mais ponderada entre a proteção ambiental e a proteção dos investimentos. Por outro lado, o Estado continua na sua longa caminhada de buscar sempre racionalizar melhor suas ações para propiciar e abarcar diferentes interesses envolvidos. Os investimentos, nessa perspectiva, apresentam excelente oportunidade de desenvolvimento sustentável, demonstrando-se como ponte entre diferentes interesses, diferentes sistemas e diferentes lógicas jurídicas.

\section{Conclusão}

Os casos da Metalclad, Tecmed e Santa Elena ilustram a existência de diferentes ordens jurídicas, em especial a proteção ambiental face à proteção dos investimentos estrangeiros. Enquadram ainda a presença de atores privados no processo de criação do direito e a interferência de diferente sistemas sociais, aqui, o econômico e o ambiental. São todos elementos que caracterizam os efeitos da globalização no direito, relação que toma, então, um papel duplo importante: de um lado, a globalização dá ao direito novas demandas e razões para sua existência e, de outro lado, o direito é, na globalização, um mecanismo capaz de lidar com as suas diferentes forças.

Essas novas demandas podem ser vistas justamente pela formação de diferentes sistemas jurídicos por atores distintos do Estado, além do Estado, por isso a necessária superação do modelo estatal do direito. No ensino do direito, é preciso desmistificar o papel estatal com o fim de fomentar o estudo do direito para além do Estado e da ordem jurídica. A discussão entre o modelo estatal do direito e o pluralismo jurídico foi trazida pela insu-

${ }^{123} \mathrm{O}$ caso Plama Consortium Limited (de Cyprus) X a República da Bulgária na Corte Permanente de Arbitragem. Disponível em: <http://www.encharter.org/index.php?id=269>. Acesso em 02. nov.2011. 
ficiência do primeiro face à realidade jurídica atual, que reflete uma pluralidade de atores influenciando na produção jurídica, assim como uma variação nos usos dos instrumentos normativos.

Nessa realidade, o pluralismo jurídico apresenta-se como forte instrumento de análise, pois não restringe a análise do direito ao âmbito estatal. Todavia, é preciso ter o cuidado de definir bem o que irá estudar nesse rol jurídico amplificado do pluralismo, para não correr o risco de seu objeto ser grande o suficiente para ser inviável de ser analisado. Nesse sentido, a superação paradigmática conta com a passagem de um conflito de normas em um conceito de direito fechado no Estado, para também um conflito entre sistemas, entre racionalidades jurídicas, entre ordens jurídicas, estatais ou não, em um conceito pluralista de direito, mais adequado aos elementos e às influências da globalização no direito.

Para o conceito de direito, restam suas características básicas como instrumento de busca por uma ordem pelas vias normativas. Retoma ainda as noções básicas de instrumento de resolução de conflitos e a regulamentação de interesses distintos, resultado do consentimento das partes, mas que a partir daí podem se tornar obrigatórias. A obrigatoriedade não estará necessariamente no conceito da norma, mas sim em como é trabalhada, seja na sua constituição, seja na sua aplicação. Nesse sentido, a obrigatoriedade e caracterização dessas normas como direito dependem do meio no qual estão sendo trabalhadas, se são tratadas como direito.

Por outro lado, para evitar que um conceito demasiado amplo do direito torne inviável a pesquisa, é melhor recorrer à escolha epistemológica de o próprio pesquisador definir exatamente os limites de sua pesquisa, dentro desse largo campo de possibilidades na realidade jurídica e como o analisa, ao invés de partir sua pesquisa de um conceito de direito dado por uma teoria.

É preciso tornar claro que o contexto pluralista não significa a supressão do Estado e nem que a ordem estatal deixa de ter importância, pelo contrario, são fortalecidos os seus papéis de defender os interesses do Estado, representados pelo interesse geral. Observar quais as forças sociais estão presentes em cada caso e como atuam é possível em um entendimento sistêmico dos setores sociais.

Uma vez superado esse impasse entre a teoria estatal do direito e o pluralismo jurídico, os mesmos casos permitem averiguar, em um contexto pluralista, alguns elementos-chave para a efetividade da proteção ambiental na sua relação com a proteção dos investimentos estrangeiros. Assim, restou claro que é complexa a relação entre proteção ambiental e proteção dos investimentos estrangeiros, mas é uma relação cujo equilíbrio e a efetividade dos interesses envolvidos começam a engatinhar. A complexidade está no próprio conflito entre proteção ambiental e proteção de investimentos, e o equilíbrio está na flexibilização e racionalização desses conflitos e interesses envolvidos.

Para especificar melhor, a relação é complexa haja vista a estrutura do ICSID, a predominância da lógica econômica, e como interfere na proteção dos investimentos, a fraca capacidade do Estado em gerir suas políticas e ações internas, que já foram estudadas neste capítulo. Além disso, é perceptível o papel influenciador dos investimentos na condução das políticas governamentais.

Nesse sentido, o caminho para o equilíbrio dessa relação segue, de um lado, para a atenção por parte do governo em gerir suas ações para que consiga aproveitar a oportunidade de desenvolvimento sustentável possível no âmbito dos investimentos estrangeiros, pois, como já ressaltado, os investimentos são o fornecimento de capital e transferência de tecnologia e uma excelente travessia sistêmica, uma ponte entre o governo, a promoção do desenvolvimento sustentável e o interesse privado.

Por outro lado, a lógica jurídica da proteção dos investimentos precisa ser flexibilizada. Pelos casos, foi possível identificar a relevância técnica do enquadramento da ação estatal como expropriação e a atenção para o lucro que o Estado teve ou deixou de ter. Além disso, tendo em vista que o motivo da medida não é fator preponderante, a flexibilização do sistema está em justamente buscar um equilíbrio entre os interesses ambientais e econômicos.

\section{Referências}

ANDRADE, Adriana; ROSSETTI, José Paschoal. Governança corporativa: fundamentos, desenvolvimento e tendências. São Paulo: Atlas, 2004.

ARON, Raymond. Paz e guerra entre as nações. Tradução Sérgio Bath. Brasília: Universidade de Brasília, Instituto de Pesquisa de Relações Internacionais; São Paulo: Imprensa Oficial do Estado de São Paulo, 2002. 
BLANC, David. L'Éco-labellisation et l'éco-certification. In: MALJEAN-DUBOIS, Sandrine. L'outil économique en droit international et européen de l'environement. Paris: La documentation française, 2002. p. 365.

BOBBIO, Norberto. Direito e poder. Tradução Nilson Moulin. São Paulo: Unesp, 2008.

BOURDIEU, Pierre. A força do direito: elementos para uma sociologia do campo jurídico.

BOURDIEU, Pierre. O poder simbólico. Rio de Janeiro: Bertand Brasil, 1989.

BULL, Hedley. A sociedade anárquica. Um estudo da ordem na política mundial. Prefácio de Williams Gonçalves. Trad. Sérgio Bath. Brasília: Universidade de Brasília, Instituto de Pesquisa de Relações Internacionais; São Paulo: Imprensa Oficial do Estado de São Paulo, 2002.

BURGENMEIER, Beat. Beat. Les nouvelles formes $\mathrm{d}$ 'investissement international et les strategies des firmes. In HUMBERT, Marc. Colloque du Greco CNRS-EFIQ. Investissement international et dynamique de l'économie mondiale. Paris: Economica, 1990.

BURGENMEIER, Beat. Economia do desenvolvimento sustentável. Tradução Ana André. Lisboa: Instituto Piaget, 2009.

CARREAU, Dominique; JUILlaRD, Patrick. Droit International économique. 3. ed. Paris: ÉditionsDalloz, 2007.

CASSESSE, Sabino. Administrative Law without the State. The Challenge of global regulation.

CLAY, Thomas; ABOIM, Luiz Claudio. Arbitragem e meio ambiente. Revista brasileira de arbitragem, v. 4, p. 32-43, 2004.

CONVENÇÃO de Washington ou a Convenção sobre Resolução de Conflitos relativos a Investimentos entre Estados e Nacionais de outros Estados. Seunomeeminglês: Convention on the Settlement of Investment Disputes between States and Nationals of other States. Disponível em: $\quad$ http://icsid.worldbank.org/ICSID/StaticFiles/ basicdoc_en-archive/9.htm>. Acesso em: 15 nov. 2011.

CONVENTION on the Settlement of Investment Disputes between States and Nationals of other States. Disponível em: <http://icsid.worldbank.org/ICSID/StaticFiles/ basicdoc_spa-archive/16.htm> Acesso em: 15 nov. 2011.

DAIBERT, Arlindo (Org.). Direito ambiental comparado. Belo Horizonte: Fórum, 2008.
DECISÃO CompañiadelDesarrollo de Santa Elena S.A., $§$ 71. Disponível em: $<$ http://icsid.worldbank.org/ICSID/Fr ontServlet?request Type $=$ CasesRH\&actionVal $=$ showDoc \&docId=DC539_En\&caseId=C152 $>$. Acesso em 20 out. 2011.

DELMAS-MARTY, Mireille. Les forces imaginantes $d u$ droit. Le relatif et l'universel. Éditions du seuil.

DINH, Nguyen Quoc; DAILLIER, Patrick; PELLET, Alain. Direito internacional publico. 2. ed. Tradução Vítor Marques Coelho. Fundação Calouste Guldenkian, 2003.

EISENMANN, Charles. Quelques problèmes de méthodologie des définitions et des classifications en science juridique. In : ÉCRITS de théorie Du droit, de droit constitutionel et d'idées politiques. s, Paris: Edition Panthéon-Assa, 2002. p. 290-305.

FARIA, José Eduardo. O direito na economia globalizada. São Paulo: Malheiros Editores, 2002.

FEBRAJO, Alberto; TEUBNER, Gunter. Autonomy and regulation in the autopoietic perspective: an introduction. In: FEBRAJO, Alberto; TEUBNER, Gunter. State, Law and economy as autopoietic systems: regulation and autonomy in a new perspective. Milan, Dott. A. GiuffrèEditore, 1992, p. 5-16.

FISCHER-LESCANO, Andreas; TEUBNER, Gunter. Regimes-Collisions: the vain search for legal unity in the fragmentation in global law. Translatet by Michelle Everson. Michigan Journal of International Law, v. 25, n. 999, p. 199-1046.

GRANT, Malcolm. Introduction. Enforcement: Who enforces? How? Whether Effective? In: CHAIRMAN, Patricia Thomas. Environmental liability: IAB Section on Business Law $7^{\text {th }}$ residential seminar on environmental law, 9-13, 1990. Switzerland, p. 213-218.

HART, H.L.A. O conceito de direito. São Paulo: WMF M. Fontes, 2009.

HUMBERT, Marc. Le concept de système industriel mondial. In: HUMBERT, Marc. Colloque du Greco CNRSEFIQ. Investissement international et dynamique de l'économie mondiale. Paris: Economica, 1990. p. 36-60, p. 45 ç.

ICSID. About ICSID. Disponível em: <http://icsid. worldbank.org/ICSID/ICSID/AboutICSID_Home. jsp>. Acesso em: 15 nov. 2011.

ICSID. Tecmed x México. Disponível em: <http://ictsd. org/i/news/4427/>. Acesso em: 01 nov. 2011. 
JHA, Veena. Part. The role of foreing direct investment. The case of India. In: WARD, Halina; BRACK, Duncan (Ed.). Trade, Investment and the Environment. Proceedings of the Royal Institute of International Affairs conference, Chatham House, London, October 1998.The Royal Institute of international Affairs, Energy and Environmental Programme. London: EarthscanPublicationsLtd, 2000.

KELSEN, Hans. Les rapports de systême entre le droit interne et le droit international public. The Hague Academy of International Law.

KELSEN, Hans. Teoría pura del derecho, Introdución a la ciência delderecho. Buenos Aires: Eudeba Editorial Universitária de Buenos Aires, 1960.

KISS, A. Introduction to International Environmental Law. $2^{\text {nd }}$ Revised Edition, , Geneva, Switzerland: UNITAR, 2005.

KISS, Alexandre. L'ordre public écologique. In FRITZ, Jean-Claude (dir.) L'ordrepubliccécologique. Towards an ecological public order. Bruyant, Bruxelles, 2005.

KOSKENNIEMI, Martti. The politics of international Law - 20 years later. The European Journal of International Law, v. 20, n. 1, p. 7-19, 2009.

LAFAY, Gérard. Nations et entreprises dans l'économie mondiale. In: HUMBERT, Marc. Colloque du Greco CNRSEFIQ. Investissement international et dynamique de l'économie mondiale. Paris: Economica, 1990. p. 61-69.

LE PRESTRE, Philippe; MARTIMORTO-ASSO, Benoît. A reforma na governança internacional do meio ambiente: os elementos do debate. In: VARELLA, Marcelo Dias; BARROS-PLATIAU, Ana Flávia (Org.). Proteção internacional do meio ambiente. Brasília: UNITAR, UniCEUB, UnB, 2009.

LIBCHABER, Rémy. L'impossible rationalité de l'ordre juridique. « L'impossible rationalité de l'ordre juridique ", Mél. Oppetit, à paraître.

LIMA, Gabriela Garcia Batista. O caso do bioetanol brasileiro: a proteção ambiental e o desenvolvimento sustentável pela atuação de empresas privadas. In: ENCONTRO NACIONAL DO CONPEDI, 19., 2010, Fortaleza. Anais... Fortaleza, 2010.

LUHMANN, Niklas. Sistemas sociales: Lineamientos para uma teoria general. Trad. Silvia Pappe y BrunhildeErker; coord por Javier Torres Nafarrete - Rubi (Barcelona): Anthropos; México: UniversidadIberoamericana; Santafé de Bogotá: CEJA, Pontifícia UniversidadJaveriana, 1998.
MALJEAN-DUBOIS, Sandrine. Le recours à L'outil économique: un habit neuf pour les politiques environnementales ? in: MALJEAN-DUBOIS, Sandrine (org). L'outil économique en droit international et européen de 1'environement. Paris: La documentation française, 2002.

MARAIS, Bertrand du. Droit Public de La régulation économique. Presses de Sicences PO etDalloz, 2004.

NEVES, Marcelo. Transconstitucionalismo. São Paulo: M. Fontes, 2009.

O CASO Metalclad x México. Disponível em: <http:// icsid.worldbank.org/ICSID/FrontServlet?requestTyp $\mathrm{e}=$ CasesRH\&action Val=showDoc\&docId=DC542_ En\&caseId=C155. $>$ Acesso em: 01 nov. 2010.

O CASO Plama Consortium Limited (de Cyprus) $\mathrm{X}$ a República da Bulgária na Corte Permanente de Arbitragem. Disponível em: <http://www.encharter.org/ index.php?id=269> Acesso em 02.nov.2010.

PIMONT, Sébastien. Peut-on réduire Le droit em théories générales ? Exemples en droit du contrat. Revue trimestrelle de droit civil, Paris, p. 417-432, juilletseptembre 2009.

REALE, Miguel. Teoria tridimensional do direito. 2. ed. rev. e atual. São Paulo: Saraiva, 1979.

ROBERT ROBERT, Sabrina. La Protection du Pouvoir de Réglementation Environnementale de l'Etat dans le Cadre du Contentieux de l'Expropriation Indirecte. Investissement International et Protection de l'Environnement. Disponível em $:<$ www.esil-sedi.eu/ english/Paris_Agora_Papers/Robert.PDF $>$. Acesso em: 22 nov. 2011.

ROMANO, Cesare P. R. The Peaceful Settlement of International Environmental Disputes. A pragmatic approach. (International Environmental Law and Policy Series, v. 56). Klumer Law International.The HagueLondon-Boston, 2000.

SAND, Peter H. Transnational Environmental Law. Lessons in Global Change. (International Environmental Law and Policy Series, v. 53). Klumer Law International. The Hague-London-Boston, 1999.

SANTOS, Boaventura de Sousa. Reconhecer para libertar: os caminhos do cosmopolitismo cultura.

SHELTON, Dinah. Techniques and procedure in international environmental Law. $2^{\text {nd }}$., Geneva, Switzerland: UNITAR, 2004. 
TEUBNER, Gunter. And if I by Beelzebub cast out Devils, ...: An Essay on the Diabolics of Network Failure. In: SPECIAL ISSUE: THE LAW OF THE NETWORK SOCIETY A TRIBUTE TO KARL-HEINZ LADEUR. German Law Journal, v. 10, n. 4, p. 115-136.

TEUBNER, Gunter. Breaking frames: Economic globalisation and the emergence of Lexmercatoria. European Journal of Social Theory, v. 5, p. 199-217, 2002.

TEUBNER, Gunter. Global Bukowina: Legal Pluralism in the World Society. In: GUNTHER Teubner (Ed.). Global Law Without a State. Dartmouth, Aldershot 1997. p. 3-28.

TEUBNER, Gunter. Global Private Regimes: Neospontaneus Law and dual constitution of autonomus sectors in world society? In: KARL-HEINZ, Ladeur (Ed.). Globalization and Public Governance, Ashgate, Aldershot. 2004. p. 71-87.

TOMAZETTE, Marlon. O Conceito Do Dumping Para A Regulamentação Multilateral Do Comércio Internacional. Prismas: Dir., Pol.Pub. e Mundial., Brasília, v. 4, n, 1, p. 194-214, jan/jul. 2007. Disponível em: <http://www. publicacoesacademicas.uniceub.br/index.php/prisma/ article/viewFile/222/223>. Acesso em 26 jul. 2011.

TRATADO para a Carta sobre Energia (Energy ChapterTreaty). Disponível em: <http://www.encharter. org/index.php?id=269> Acesso em 02 nov. 2011.

TRIEPEL, Carl Heinrich. Les rapports entre Le droit interne et le droit international. ThaHagueAcademyofinternational.
UNCOMMON GOODS: On Environmental Virtues And Voluntary Carbon Offsets. In: Harvard Law Review; Jun2010, v. 123 Issue 8, p2065-2087, 23p. editors home Page: <http://www.harvardlawreview.org/>. Artigo disponível em: <http://web.ebscohost.com/ehost/ pdfviewer/pdfviewer?vid=7\&hid=110\&sid=d30426a 1 d3b0-492e-ab91-23de84b7239d\%40sessionmgr114>. Acesso em: 26.07.2011.

VARELLA, Marcelo Dias. A crescente complexidade do sistema jurídico internacional. Alguns problemas de coerência sistêmica. Revista de Informação Legislativa, Brasília, ano 43, n. 167 jul./ set. 2005.

VERDROSS, Alfred. Le fondement du droit international. The Hague Academy of International Law.

WALINE, Marcel. Empirisme et conceptualism dans la méthode juridique : faut-il tuer les catégories juridiques? Mélanges Jean Badin.

WEISS, Edith Brown; JACKSON, John J. O enquadramento dos conflitos entre meio ambiente e comércio. In: VARELLA, Marcelo Dias; BARROSPLATIAU, Ana Flávia (Org.). Proteção internacional do meio ambiente. Brasília: UNITAR, UniCEUB, UnB, 2009. p. 295-344.

WIGHT, Martin. A política do poder. 2. ed. Brasília: Universidade de Brasília, Instituto de Pesquisa de Relações Internacionais; São Paulo: Imprensa Oficial do Estado de São Paulo, 2002.

WITTGENSTEIN, Ludwig. Philosophical Investigations. Translated by G. E. M. Anscombe.3a ed. Blackwell Oxford UK \& Cambridge, USA, 1967. 
Para publicar na Revista de Direito Internacional, acesse o endereço eletrônico www.rdi.uniceub.br ou www.brazilianjournal.org.

Observe as normas de publicação, para facilitar e agilizar o trabalho de edição. 